\title{
The neuropsychology of schizophrenia
}

Citation for published version (APA):

Krabbendam, L., \& Jolles, J. (2002). The neuropsychology of schizophrenia. In Biological Psychiatry (Vol. 2, pp. 631-647). Wiley.

Document status and date:

Published: 01/01/2002

Document Version:

Publisher's PDF, also known as Version of record

\section{Please check the document version of this publication:}

- A submitted manuscript is the version of the article upon submission and before peer-review. There can be important differences between the submitted version and the official published version of record.

People interested in the research are advised to contact the author for the final version of the publication, or visit the DOI to the publisher's website.

- The final author version and the galley proof are versions of the publication after peer review.

- The final published version features the final layout of the paper including the volume, issue and page numbers.

Link to publication

\footnotetext{
General rights rights.

- You may freely distribute the URL identifying the publication in the public portal. please follow below link for the End User Agreement:

www.umlib.nl/taverne-license

Take down policy

If you believe that this document breaches copyright please contact us at:

repository@maastrichtuniversity.nl

providing details and we will investigate your claim.
}

Copyright and moral rights for the publications made accessible in the public portal are retained by the authors and/or other copyright owners and it is a condition of accessing publications that users recognise and abide by the legal requirements associated with these

- Users may download and print one copy of any publication from the public portal for the purpose of private study or research.

- You may not further distribute the material or use it for any profit-making activity or commercial gain

If the publication is distributed under the terms of Article $25 \mathrm{fa}$ of the Dutch Copyright Act, indicated by the "Taverne" license above, 


\title{
The Neuropsychology of Schizophrenia
}

\author{
L. Krabbendam and J. Jolles
}

\section{INTRODUCTION}

Schizophrenia is a major psychiatric disorder characterized by a disruption in affective, cognitive and social domains, which results in compromised ability to adapt to a changing environment and to function adequately in the community. The point prevalence, expressed as the number of cases per 1000 persons at risk, is estimated at between 1.4 and 1.6, and the lifetime prevalence ranges from $0.5 \%$ to $1.0 \%$ of the population (Jablensky, 1995). The disorder usually manifests itself between the ages of 18 and 25 , but according to current neurodevelopmental models of schizophrenia may already begin during prenatal development. More specifically, it is hypothesized that a failure occurs during the period of cell migration, leading to non-optimal connections between brain areas (e.g., Weinberger, 1987). The onset of psychotic symptoms is so much later, when the affected part of the brain matures and is called 'on line' (Weinberger, 1987).

With respect to the neuropsychology of schizophrenia, the notion of deterioration in cognitive and behavioural functions was implicit in the initial conceptualization of the disorder. Kraepelin (1919) labelled the disorder 'dementia praecox', defining it as an irreversible deteriorative condition. In past decades, numerous studies have yielded evidence for cognitive deficits in patients with schizophrenia. In the 1960s, investigations into disrupted attentional functions started with systematic experimental investigations of reaction time parameters in the differentiation of schizophrenics from non-psychiatric individuals. Clinical research in the same period had shown that schizophrenic patients performed abnormally on measures of general intellectual functioning (e.g., Heaton and Crowley, 1981). Indeed, it turned out that when a group of patients with schizophrenia are compared to healthy controls on a neuropsychological test battery, performance of the patient group was worse on almost all of the tests and comparable to the performance of patients with known neurological damage. However, a description of the symptoms, cognition and behaviour of schizophrenics in terms of the dichotomy 'organic' versus 'functional' has not proved very fruitful. Nowadays, schizophrenia is considered as a psychiatric disorder with neuropsychological correlates. This more accurately characterizes the illness and enables the investigation of specific brain-behaviour relationships which underlie the variability of symptoms and neurobehavioural systems which may be affected.

In this chapter we present the neuropsychological aspects of schizophrenia, with an emphasis upon the major cognitive and behavioural functions that are affected. We do not attempt to give an elaborate overview of clinical neuropsychological research which has shown, generally, deficits in performance of schizophrenic subjects. Rather, we focus on neurocognitive processes involved in the expression of the disease and elaborate on possibly relevant modulatory factors, and on current models which attempt to understand the behavioural expression of the disease. Attentional functions, executive functioning and memory — notably working memory - are described in relation to the various experimental techniques used to measure neurocognitive processes. Important notions are evaluated such as those regarding the processing of context, theory of mind and monitoring. We will also consider vulnerability factors such as genetic and environmental factors and the relation with factors such as medication, cognitive therapy and the course of deficits. Closing paragraphs are devoted to a description of the functional significance of the neurocognitive and behavioural changes to allow better understanding of the symptoms and neurobehavioural profile of schizophrenics. The chapter does not contain material concerning neurological or 'brain localizational' aspects of schizophrenia, because Chapter XVII-8 in this book is dedicated to that subject.

\section{THE NATURE OF THE NEUROCOGNITIVE DEFICITS IN SCHIZOPHRENIA}

The range of deficits in schizophrenia is extremely broad. Roughly, when a battery of neuropsychological tests is administered to a group of patients with chronic schizophrenia, mean performance of the group will be significantly below normal performance on at least half of the tests. Reviewing all findings would be nearly impossible, and would probably obscure the central issues in this review. Therefore, this section summarizes research on three cognitive domains: attention, memory and executive function. These were chosen because impairments on these domains have been consistently implicated in schizophrenia research, and sophisticated paradigms have been developed to elucidate the nature of dysfunction in these domains.

\begin{abstract}
Attentional Functions
Both clinical descriptions and subjective accounts of schizophrenia emphasize attentional deficits. Attention is a multifactorial construct, including the ability to maintain an alert state, to orient to novel stimuli, to filter relevant information and to rapidly discriminate stimuli for some duration of time. Two aspects of attention that have received particular attention in schizophrenia research are sustained and selective attention. Sustained attention refers to the capacity to maintain a state of readiness to respond to small changes in the environment. Selective attention is the capacity to focus while ignoring irrelevant information.
\end{abstract}

\section{Sustained Attention}

A widely used test to assess sustained attention is the Continuous Performance Test (CPT). In this test, stimuli, usually letters or 
digits, are presented briefly one at a time in a random order. The subject has to respond when a certain target stimulus appears - in some variants of the task only when preceded by a certain cue. Patients with schizophrenia usually display reduced sensitivity on the CPT (Addington and Addington, 1997; Nuechterlein et al., 1994; Van den Bosch et al., 1996). This deficit is particularly pronounced on versions with high processing loads; for example, tasks with rapid stimulus presentation, stimulus degradation or when the previous stimulus must be remembered to make the current decision (Nelson et al., 1998; Nuechterlein et al., 1994). Although impaired CPT performance is a robust finding, there is as yet no consensus concerning the precise mechanism of the impaired performance. Cohen and Servan-Schreiber (1993) have constructed a computer simulation model of the CPT and other tasks to test their hypothesis that the core cognitive deficit in schizophrenia is 'an impairment in maintaining contextual information over time and in using that information to inhibit inappropriate responses'. They showed that a single disturbance to the module responsible for representing and maintaining context yielded performance impairments similar to those seen in schizophrenia. In a subsequent study, a variant of the CPT designed to elicit deficits in the processing of contextual information was administered to patients with first-episode schizophrenia and patients later in the course of their illness (Servan-Schreiber et al., 1996). Specifically, the frequency of cue-target sequences (e.g., A-X) was increased, to introduce a strong tendency to respond to the letter X. Thus, in the non-cue followed by target condition (e.g., B-X), subjects had to rely on the previous letter as a context to inhibit the response to $\mathrm{X}$. Two delay intervals between cue and target were used, namely $750 \mathrm{~ms}$ and $5 \mathrm{~s}$. The prediction was that patients with schizophrenia would perform worse in the long delay condition, particularly with regard to the number of non-cue-target errors, because of a reduced capacity to maintain context. Indeed, the performance of unmedicated patients followed the pattern predicted by the context hypothesis. The deficit was worse in unmedicated patients with a longer course of the illness. The authors interpreted the results as support for the view that a single deficit in the processing of context may underlie the cognitive impairments in schizophrenia.

However, a recent study has called this explanation into question and instead suggested that a problem in encoding is at the core of deficits on this type of tasks. This study used variations of the CPT to investigate possible mechanisms of impairment, including stimulus-response mapping, use of context and working memory (Elvevåg et al., 2000). The amount of stimulus-response mapping that was required was varied by using two kinds of cue-target pairs, namely with and without inherent instructions (e.g., 'ready' followed by 'press' versus 'one' followed by "nine"). As in the study by Servan-Schreiber and colleagues (1996), the sensitivity to context problems was manipulated by varying the frequency of the target stimuli; to investigate the involvement of working memory, two delay intervals between the cue and the target were used (namely, $1000 \mathrm{~ms}$ and $3000 \mathrm{~ms}$ ). These tasks were administered to 20 inpatients with schizophrenia and 30 healthy volunteers. As expected, the patients performed significantly worse on all tasks than did the comparison subjects. Contrary to expectations, however, there was no differential impact of any of the task manipulations on the speed of performance of the patients. The only effect of the task manipulations was that patients made more errors at short delay intervals. This pattern of results suggests difficulties in the rapid encoding of information, leading to a differentially impaired performance in short delay intervals between stimuli, where the second stimulus interferes with constructing a representation of the first. In sum, impairment on the CPT is a robust finding in schizophrenia, but there might be more than one pathway to poor performance. One explanation suggests a deficit in the processing of context, but it has also been proposed that a dysfunction of rapid encoding is at the core of impaired CPT performance.

\section{Selective Attention}

Selective attention is often assessed using the Stroop Colour-Word Test (SCWT; Stroop, 1935). The SCWT has an interference component that requires the subject to inhibit an automated response (word reading) in favour of a less salient aspect (colour naming). A typical Stroop task consists of three conditions: (1) word reading; (2) colour naming; and (3) interference (colour names printed in conflicting colours). Several studies have demonstrated impaired performance on the SCWT, particularly in the interference condition (Barch and Carter, 1998; Krabbendam et al., 2000; Liddle and Morris, 1991). Recently, investigators have begun to use singletrial versions of the Stroop task, instead of lists of stimuli printed on cards, and included a congruent condition in which the word and the print colour are the same. Typically, reaction times are shorter in congruent compared to neutral conditions, when there is no relation between colour and semantic meaning (e.g., the word chair printed in blue). This phenomenon is known as Stroop facilitation. Studies using a single-trial Stroop task have yielded evidence for an increased facilitation effect in schizophrenia (Carter et al., 1992; Cohen et al., 1999). This effect was further examined by Barch and colleagues (1999). Forty patients with schizophrenia and 20 healthy controls were administered blocks of congruent, incongruent and neutral trials. In each trial, a stimulus was presented in one of four colours: red, blue, green or purple. The task was to name the colour in which the stimulus was printed as quickly as possible. The congruent trials consisted of colour names presented in its own colour. The incongruent condition consisted of colour names presented in one of the three remaining colours. The neutral trials consisted of either words or squares, printed in one of the four colours. Patients with schizophrenia showed increased facilitation compared to normal controls in both word and nonword neutral conditions. In the non-word condition, the stimulus does not interfere with the (verbal) colour-naming response. Thus, an increased facilitation effect in this condition means that part of this effect can be attributed to a greater influence of the word in the congruent condition. Apparently, patients are less able than controls to ignore the word dimension in this condition, possibly due to selective attention deficits.

\section{Memory}

\section{Verbal Memory and Intentional Learning}

Memory impairment in patients with schizophrenia has been reported in several studies (Landrø, 1994; McKenna et al., 1990; Saykin et al., 1991). Yet, poor memory may be the consequence of a number of factors, including medication or psychopathology. To the extent that this is true, these factors cannot completely account for the memory deficit in schizophrenia. A recent meta-analysis of 70 studies documented a significant and wide-ranging deficit, which was not due to potential confounding factors such as medication status, age or severity of psychopathology (Aleman et al., 1999). Verbal memory, including story recall and word list learning, seems to be more severely affected than non-verbal memory (Saykin et al., 1991), although this difference was not significant in the meta-analysis by Aleman and colleagues (1999). Free recall is particularly affected (Beatty et al., 1993; Paulsen et al., 1995), indicating a deficit of retrieval of information. However, impaired recognition is sometimes observed, at least in the more severely disturbed patients (Clare et al., 1993; Landrø, 1994), which suggests that consolidation of information may also be impaired. It has been suggested that the memory deficit in schizophrenia is in some respects analogous to the classical amnesic syndrome with intact implicit memory, relative sparing of short-term recall, an accelerated forgetting and poor long-term recall (McKenna et al., 
1990). This view is not supported by the meta-analysis by Aleman and colleagues, which yielded evidence for an impaired short-term memory and a normal rate of forgetting (Aleman et al., 1999). Nevertheless, a relative sparing of implicit learning and memory has been reported in several studies (Clare et al., 1993; Kern et al., 1997).

\section{Working Memory}

An aspect of memory that has received particular attention in schizophrenia research is working memory. Working memory is the type of memory that is active and relevant only for a short period of time and is defined in content and duration by the action it subserves (Baddeley and Hitch, 1974; Fuster, 1989). Working memory accounts for the ability to guide behaviour by cognitive representations in the face of varying degrees of distraction and thus to base behaviour on thoughts and intentions rather than on direct stimulation. The term is related to the notion of context introduced in the previous section. According to Baddeley and Hitch, working memory consists of a superordinate central executive system and two slave systems for the transient storage of visuospatial and verbal information (the visuospatial sketchpad and phonological loop). Unfortunately, the term working memory is used in different ways (Baddeley and Hitch, 1994; Perry et al., 2001). A major source of confusion is that sometimes only involvement of the slave systems is required to perform the working memory tasks, and sometimes the central executive system as well. Perry et al. (2001) propose to distinguish between transient 'online' storage, when only storage and retrieval of information are required, and executivefunctioning working memory, when in addition to storage and retrieval manipulation of the information is required. The distinction between forward and backward digit spans may correspond roughly to the distinction between transient storage and executive function working memory. Another example of transient online storage is the delayed response paradigm employed by Goldman-Rakic and colleagues to investigate working memory in non-human primates (Funahashi et al., 1989; Goldman and Rosvold, 1970). There are numerous tasks that tap into executive-functioning working memory, such as the Tower of London (Shallice, 1982) and the Wisconsin Card Sorting Test (WCST; Berg, 1948; Heaton, 1981). Although these tasks may not be designed specifically to assess working memory, they do require to keep in mind instructions, goals and concepts (Goldman-Rakic, 1994). Does the working memory impairment in schizophrenia involve both transient 'online' storage and executive functioning, or is the first aspect relatively intact? In general, the findings point to an impairment of both functions, although the picture is not entirely consistent. Several studies have demonstrated impaired performance on transient storage tasks in schizophrenia (e.g., Fleming et al., 1997; Park and Holzman, 1992; Spitzer, 1993; Pantelis et al., 1997). For example, Pantelis et al. (1997), using tests from the Cambridge Neuropsychological Test Automated battery (CANTAB), found evidence for impaired performance on a task that required the subject to remember a sequence of squares presented on a screen. Park and Holzman (1992) also found evidence for impaired transient storage on a spatial working memory task. However, in the same sample auditory working memory assessed with digit span forward was intact. Also, in a comparison of monozygotic twins discordant for schizophrenia the affected twin performed worse than the healthy twin in the backward but not in the forward condition (Goldberg et al., 1990). However, most studies point to significant impairments in both digit span tasks. This is also apparent from the meta-analysis by Aleman et al. (1999). Data from 18 studies on forward span and seven studies on backward span yielded no significant difference in effect size between the two spans.

\section{Semantic Memory}

The term semantic memory refers to stored information that is impersonal, and includes knowledge of words and their meanings, knowledge about objects and their categorizations, and general information about the world. The term was introduced by Tulving to distinguish this form of memory from episodic memory, the memory for personally experienced events (Tulving, 1983). Both forms of memory are considered to be closely related and in continuous interaction with each other. The notion of impaired semantic knowledge in schizophrenia dates from several decades ago. Cameron has suggested that the core feature of thought disorders in schizophrenia was overinclusive thinking, a vagueness of boundaries between concepts making them overextensive and able to accommodate logical contradictions (Cameron, 1939). Subsequent studies have provided support for this notion (Chen et al., 1994; Cutting et al., 1987; Payne, 1973). The study by Chen and colleagues used a task that required subjects to verify words as members or non-members of a conceptual category. The words differed in their degree of semantic relationship to the category. Control subjects had the longest reaction time for items at the borderline of the category (e.g., penguin in the category of birds). In contrast, patients with schizophrenia took longest to respond to items that were outside the category, but semantically related to it (e.g., airplane in the category of birds). According to the authors, this pattern of results suggests an outward shift of semantic category boundaries in schizophrenia. Overinclusive thinking may be explained in terms of an activated semantic network, in which activation spreads faster than normal to other related concepts and thereby crosses over the usual boundaries of concepts (Spitzer, 1993). Such heightened activation has been experimentally demonstrated using semantic priming paradigms. Patients with schizophrenia show more semantic priming (Kwapil et al., 1990; Maher et al., 1996), most notably when the prime and the target are indirectly semantically related (e.g., lemon - sweet) (Spitzer et al., 1993). Thus, semantic memory in schizophrenia may be qualitatively different from semantic memory in healthy controls.

\section{Executive Functions}

\section{The Wisconsin Card Sorting Test}

The executive functions comprise capacities for volitional activity, forward planning and self-regulation (Lezak, 1995). The most widely used test of executive functions is the Wisconsin Card Sorting Test (WCST). The WCST is a complex test involving concept formation, working memory and cognitive flexibility. A large amount of literature suggests impaired performance in schizophrenia in terms of increased numbers of perseverative errors and fewer categories achieved, when compared to healthy controls (Goldberg et al., 1994; Haut et al., 1996; Morice, 1990; Sullivan et al., 1993). However, performance on the WCST seems to be heterogeneous (Braff et al., 1991) with poor performance restricted to a subgroup of patients characterized by the presence of other cognitive deficits (Bellini et al., 1991; Goldstein et al., 1996), as well as negative symptoms and more hospitalizations (Butler et al., 1992). Other authors have directed attention to the unusual and strong relationship between performance on the WCST and general intellectual ability, ageing and education, which suggests that non-specific factors account for a substantial proportion of WCST performance in schizophrenia (Heinrichs, 1990; Stratta et al., 1993; Heinrichs and Zakzanis, 1998). Given the complexity of the WCST, several studies have attempted to identify specific processes that underlie test performance. Gold et al. (1997) have suggested that working memory, assessed by a novel measure called 'letter-number span', is a critical determinant 
of WCST performance in schizophrenia. Yet, even this simpler task involves functions other than working memory, for example, aspects of executive functions. This measure involved the auditory presentation of a mixed series of alternating numbers and letters, the task being to respond by first saying the numbers in order from the smallest to the largest, followed by saying the letters in alphabetical order. In another study, a significant correlation between WCST perseverative errors and time spent on the interference test of the SCWT was observed and the authors concluded that these tests have the involvement of mental control and cognitive flexibility in common (Rossi et al., 1997a). In sum, the WCST is a widely used measure of executive functions, but due to its complexity it is unclear which cognitive processes underlie poor performance, while several studies have indicated that part of the variance in WCST performance is shared with general factors, such as intellectual ability, ageing and number of hospitalizations.

\section{Tower of London}

Shallice (1982) introduced this test, derived from the Tower of Hanoi puzzle. The task is to move a number of coloured beads placed on three upright poles so as to reproduce a certain pattern. The subject must look ahead and divide the task into a series of subtasks, and carry these out in the right order to obtain the solution in a minimum number of moves. Pantelis et al. (1997) used an automated version of this task, which is part of the CANTAB. This allowed for the registration of planning and execution latencies. Performance of hospitalized patients with schizophrenia $(N=36)$ was compared to that of normal subjects and patients with neurological disorders. The patients with schizophrenia were able to complete the task, but made fewer solutions within the minimum number of moves, and required more moves for completion compared to the healthy volunteers. Also, time needed for completion was longer for the patients with schizophrenia than for the healthy volunteers. The patients with schizophrenia were not impaired in their 'initial thinking' (planning) latencies, but had significantly prolonged 'subsequent thinking' (execution) latencies. This pattern resembled that of the group with frontal lobe lesions and contrasted with the prolonged 'initial thinking' time seen in Parkinson's disease. However, in a sample of 24 outpatients with schizophrenia, performance on the Tower of London was normal, whereas on the WCST and the Behavioural Assessment of the Dysexecutive Syndrome (BADS; see next section) performance was impaired (Krabbendam et al., 1999). Although this study did not record time needed for completion, the findings do suggest that the Tower of London is less sensitive to deficits of planning than the other two tests.

\section{The Behavioural Assessment of the Dysexecutive Syndrome}

It has been difficult to develop satisfactory methods for demonstrating and quantifying executive functions, because the structured nature of most neuropsychological examinations gives the patient insufficient opportunity to make use of these functions (Lezak, 1982). Moreover, the standard tests tend to focus on individual components of executive functioning. Yet, what is impaired in patients with impaired executive functions is the ability to initiate, integrate and monitor the use of these components (Shallice and Burgess, 1991). Patients with gross difficulties in daily life may therefore perform within normal limits on the standard executive tests. To overcome these shortcomings, a test battery has been developed, with the aim of being able to predict which everyday problems would arise as a result of impaired executive functioning. The Behavioural Assessment of the Dysexecutive Syndrome (BADS; Wilson et al., 1996) presents the subject with a series of unstructured tasks that are designed to reflect daily life situations. For example, in the subtest Modified Six Elements the subject is told to do six tasks (dictation, simple arithmetic and picture naming, each of which has two sections) in 10 minutes. It is impossible to complete all tasks in 10 minutes, but the subject should do at least something of all six sections, without breaking certain rules. Recent findings suggested that the BADS can indeed identify executive deficits in schizophrenia (Evans et al., 1997; Krabbendam et al., 1999). Significant impairments on the BADS were even found in a subgroup who displayed intact general intellectual functioning (Evans et al., 1997).

\section{General Intelligence}

Global intellectual decline is a common finding in schizophrenia (Braff et al., 1991; Blanchard and Neale, 1994; see Aylward et al., 1984, for a review of earlier studies), even in first-episode patients (e.g., Bilder et al., 2000; Mohamed et al., 1999). However, a decline in intelligence quotient (IQ) may not be universal. A cluster analysis of neurocognitive data of 104 patients with chronic schizophrenia yielded a five-cluster solution, two being characterized by average IQ and a normal cognitive profile, except for motor impairments and slightly higher than normal recall intrusion rates, respectively (Heinrichs and Awad, 1993; Heinrichs et al., 1997). Only one cluster (24\% of the patients) suggested generalized impairment, the other two clusters comprising patients with low-average IQ and a selective executive or executive-motor dysfunction. In a sample of 117 consecutively admitted patients with chronic schizophrenia, Weickert and colleagues (2000) found a general intellectual decline of 10 points or more from premorbid levels, estimated by means of reading scores, in 60 patients $(51 \%)$. The remaining patients showed no significant decline relative to estimated premorbid IQ. Half of these patients (i.e., $25 \%$ of the total sample) had impaired premorbid IQs and half displayed average estimated premorbid intellectual levels. This latter group showed cognitive profiles similar to normal, except for the presence of executive function deficits and, possibly, attention and encoding. This pattern of compromised executive functions in the presence of normal intelligence has been described previously (Elliot $e t$ al., 1995; Evans et al., 1997; Heinrichs and Awad, 1993; Shallice et al., 1991).

The concept of intelligence encompasses a range of cognitive functions and abilities. Therefore, intelligence tests are not well suited to examine specific patterns of deficits, unless the findings are considered in the context of detailed cognitive assessments. Nonetheless, one advantage is associated with the use of intelligence tests. That is, because intelligence tests are widely used in schools, conscript cohorts and hospitals, large data sets are available. This allows for the possibility to investigate the course of the intellectual impairment from premorbid to postmorbid state. Findings based on these data will be discussed below in the sections on course of the deficits and on cognitive vulnerability indicators.

\section{Integrative Approaches}

\section{Generalized Deficit}

An issue that continues to raise considerable debate is whether the cognitive deficit in schizophrenia can best be characterized in terms of a generalized or a specific impairment. Given the broad range of cognitive deficits, the most parsimonious explanation would be that patients with schizophrenia have a generalized deficit and perform poorly on all tests (Blanchard and Neale, 1994; Mohamed et al., 1999). However, not all deficits fit such an explanation. Some abnormalities of attention and information processing can be demonstrated on tasks that require minimal effort, for example defective sensory gating. Other deficits result in superior rather than 
deficient performance, for example on latent inhibition paradigms (Braff, 1993; see also below). Moreover, within the context of this generalized deficit, the question becomes whether patients perform disproportionately worse on some tests (Green, 1998).

Several candidates for such a differential deficit have been proposed, notably attention (Weickert et al., 2000), verbal learning and memory (Bilder et al., 2000; McKenna et al., 1990; Saykin et al., 1991) and executive functions (Evans et al., 1997; Riley et al., 2000; Weickert et al., 2000). However, the findings of a differential deficit should be interpreted in the context of the psychometric limitations of the neuropsychological tests. As Chapman and Chapman (1978) have pointed out, a differential deficit in performance does not necessarily indicate a differential deficit in ability. To measure differential deficit in ability, tests must be matched on psychometric characteristics of test reliability and test difficulty. In addition, differential discriminating power of the various tasks may obscure any differential deficits in ability. The study by Saykin and co-workers (1991) used standardized residual scores (Chapman and Chapman, 1989) as an alternative strategy for the elaborate procedures for matching tasks on their psychometric properties. However, Blanchard and Neale (1994) have argued that this method does not allow for inferences regarding differential abilities, when used in the context of a generalized performance deficit. Thus, given the psychometric limitations of currently available cognitive tests, findings of generalized and differential deficits must be interpreted with caution.

\section{Processing of Context}

In normal information processing, perception is dependent on an interaction between the external stimuli and memories of regularities in previous input. When appropriate material from memory is activated, this results in expectancies and response biases, so that temporal and spatial redundancy is used to reduce informationprocessing demands. Hemsley $(1994,1987)$ has proposed that the rapid and automatic assessment of the significance of the sensory input on the basis of past regularities is impaired in schizophrenia. According to this model, it should be possible to develop tasks at which patients with schizophrenia perform better than normal controls, namely when the latter group forms expectancies which are inappropriate to the stimulus presented. The latent inhibition paradigm, derived from animal studies, is an example of a task at which patients display superior performance (Hemsley, 1993; Lubow and Gewirtz, 1995). In the first stage of the paradigm, a stimulus is repeatedly presented to the subjects; in the second stage, this pre-exposed stimulus is paired with reinforcement in a classical or instrumental learning procedure. Pre-exposed subjects learn this association much more slowly than subjects who did not receive the first stage of pre-exposure. This effect is interpreted as a reduction in the deployment of attention to a stimulus that is redundant, since it has no consequences according to the learned regularity. Patients with acute schizophrenia perform better than normals in the pre-exposure condition, apparently due to their continuing to attend to the redundant stimulus (Baruch et al., 1988; Gray et al., 1992). Patients with chronic schizophrenia and patients who have been treated with antipsychotic medication for several weeks show no differences in performance on latent inhibition tasks compared to healthy individuals. The link between abnormal latent inhibition and psychotic symptoms may be that, following a loosening of the perceptual context, attention may be captured by incidental details of the environment. These details would normally not reach awareness, but the conscious registration initiates a search for the reasons for its occurrence (Hemsley, 1994). According to the model, symptoms such as poverty of speech, social withdrawal and retardation are learned over time to cope with the high levels of information overloads. However, this model cannot easily account for the finding that negative symptoms may be present at a very early stage of the illness (Arndt et al., 1995).

\section{Computational Models}

Based on computer simulation models that specify mechanisms of normal information processing underlying task performance, Cohen and Servan-Schreiber (1992; see also above) have also emphasized the role of context information. According to their model, a single mechanism that is responsible for the representation and maintenance of context information may account for the pervasive cognitive impairment in schizophrenia. Given the similarities between definitions of context and working memory, this view is in line with the proposal by other authors that a reduction of working memory capacity is the core dysfunction in schizophrenia (Fleming et al., 1994; Goldman-Rakic, 1994). Processing of context information may be relevant to almost all cognitive tasks, although it is particularly important in tasks that require to maintain information over time and to inhibit habitual responses. Cohen and Servan-Schreiber have constructed computer simulation models of three tasks: the SCWT, the Continuous Performance Test and a lexical disambiguation task (Cohen et al., 1999; Cohen and Servan-Schreiber, 1992). Each model consisted of an input module for representing externally presented stimuli, an output module for producing a response, an associative module for relating stimuli to appropriate responses, and a context module that can regulate the flow of information through the associative module. Reciprocal connections between the associative module and the context module allowed stimuli presented to the network to help establish the context, which in turn can influence the processing of subsequent stimuli. The context module carried out both the maintenance of information and the inhibition of irrelevant information, indicating that both memory and inhibition reflect the operation of a single mechanism. When this context module was disturbed, the model predicted changes in performance similar to the actual performance deficits of patients with schizophrenia. This was the case for each of the three computer models.

\section{Course of the Deficits}

Two contrasting hypotheses have been postulated concerning the natural course of the cognitive deficits in schizophrenia. According to the first, the cognitive deficits follow a course analogous to progressive dementia, consistent with the view that schizophrenia involves a neurodegenerative process. In the second view, the cognitive deficits are considered relatively stable, in accordance with a neurodevelopmental model of schizophrenia. During recent decades, both longitudinal and cross-sectional studies of cognitive deficits have mainly supported the neurodevelopmental hypothesis (Goldberg et al., 1993b; Rund, 1998). Mild cognitive deficits may be present premorbidly, as indicated by studies following large samples of children of parents with schizophrenia from childhood into the age of risk, like the Israeli High-Risk Study (Mirsky et al., 1995b) and the New York High-Risk Project (Cornblatt et al., 1999). Prospective studies of large birth cohorts have supported the association between cognitive deficits in childhood and adult psychosis (Cannon et al., 1999; Jones et al., 1994a, 1994b; Kremen et al., 1998). Also, there is evidence that subgroups of patients with schizophrenia show lower estimates of premorbid IQ than controls on the basis of reading scores (Crawford et al., 1992; Gilvarry et al., 2000).

Following the onset of the first psychotic episode, most patients experience a substantial decline in cognitive functions compared to their premorbid level (Goldberg et al., 1993b; Weickert et al., 2000). That onset of the psychotic symptoms and the cognitive 
decline do not occur in childhood but so much later may be because only then does the affected part of the brain mature and is called 'on line' (Weinberger, 1987). Most cognitive deficits persist during clinical remission (Cantor Graae et al., 1995; Goldberg et al., 1993b; Nopoulos et al., 1994; Nuechterlein et al., 1994). Once established early in the course of the disorder, the deficits seem to be relatively stable over the years (Goldberg et al., 1993b; Rund, 1998). Thus, cross-sectional studies of first-episode patients have shown patterns of deficits similar to patients later in the course of their illness (Bilder et al., 2000; Heaton et al., 1994; Mohamed et al., 1999; Saykin et al., 1994). Furthermore, crosssectional studies across a wide age range have suggested stable cognitive impairments (Eyler Zorrilla et al., 2000). Most recent longitudinal studies also point to a stability of cognitive functioning (Censits et al., 1997; Gold et al., 1999), early in the course of the disorder (Hoff et al., 1999; Nopoulos et al., 1994) but also in older patients (Harvey et al., 1995). Yet, the time between baseline and follow-up was 1 or 2 years in most studies, except for the study by Gold et al. (5 years) and Hoff et al. (5 years), indicating the need for studies of longer duration.

However, the neurodevelopmental model cannot account for all findings. A subgroup of geriatric patients with chronic schizophrenia displays severe cognitive and functional impairments that implicate decline at some time point after the onset of illness (Friedman et al., 1999a; Harvey et al., 1999a, 1999b). Also, it has been suggested that progressive age-related deterioration in schizophrenia occurs in specific cognitive functions, notably abstraction ability (Fucetola et al., 2000) or processing resources (Granholm et al., 2000). This is in line with the view recently put forward by Lieberman (1999), that it is premature to reject a role for neurodegenerative processes in the pathophysiology of schizophrenia.

\section{SYMPTOMS OF SCHIZOPHRENIA AND COGNITIVE DEFICITS}

\section{Positive and Negative Syndromes}

Attempts to link the cognitive deficits to symptoms of schizophrenia have mainly focused on the relation with positive and negative syndromes (see Strauss, 1993, for a review of earlier studies). The main approach has been to correlate the degree of cognitive deficits to the severity of symptoms of both dimensions. Negative symptoms have been found to be associated with deficits in verbal and visual memory, visual/motor processing and impaired executive functions (Berman et al., 1997; Capleton, 1996; O'Leary et al., 2000; Rossi et al., 1997b). Positive symptoms have been found to co-occur with impaired auditory attention and verbal memory (Berman et al., 1997; Green and Walker, 1986), but the evidence is more in favour of independence between positive symptoms and neuropsychological deficits (O'Leary et al., 2000; Voruganti et al., 1997). In accordance with this, several studies have shown that the paranoid subtype, characterized by delusions and hallucinations, is associated with better performance in memory, attention and executive functions, compared to the other subtypes (Seltzer et al., 1997; see Zalewski et al., 1998, for a review).

Liddle (1987) has proposed that the symptoms of disorganization can best be seen as a separate cluster within the positive dimension, which has been confirmed by subsequent factor analyses (Johnstone and Frith, 1996). The dimension of disorganization might be associated with impaired cognitive functions, notably impaired selective attention and inhibition (Liddle and Morris, 1991; Van der Does et al., 1996); low verbal IQ and impaired concept attainment (O'Leary et al., 2000); and impaired visual and auditory attention (Brekke et al., 1995).
However, correlations between symptoms and deficits are generally quite modest. It seems that most of the variance of symptoms must be attributed to factors other than neurocognition. In fact, several studies have found that symptoms and neurocognition are independent. This is particularly the case for the positive symptom cluster (Brekke et al., 1995; O'Leary et al., 2000; Voruganti et al., 1997), but similar results have been found for negative symptoms as well (Seaton et al., 1999; Suslow et al., 1998). Further, a major drawback of this correlational approach is that it is descriptive instead of explanatory, which means that it offers no insight into the reason for the association (Green, 1998). An alternative approach has been to take individual symptoms of psychosis as the starting point and examine possible cognitive mechanisms that may underlie them. In the next section, two cognitive accounts of psychotic symptoms will be discussed, namely theory of mind and self-monitoring.

\section{Theory of Mind}

Theory of mind refers to the ability to explain the behaviour of others in terms of their mental states (Premack and Woodruff, 1978). In normal children, this ability emerges in the pre-school years, manifested for example in the use of mental state expressions in their language and the understanding of the consequences of false belief, (e.g., understanding the actions of characters within stories that are a result of their false beliefs about the state of the world) (Leslie, 1987). In recent decades, most research on theory of mind, in humans has focused on children with autism. There is evidence that autistic children have a specific deficit in theory of mind that is apparent, for example, from deficits in pretend play and difficulties in the understanding of false belief (Baron-Cohen et al., 1985). In schizophrenia, interest in theory of mind abilities has been less explicit, although several studies of social competence in schizophrenia did refer to the ability to infer mental states in others (e.g., Cutting and Murphy, 1990; Diamond, 1956). For example, Diamond (1956) presented evidence to support the notion that patients with schizophrenia are unable adequately to internalize the point of view of others. Frith (1992) has applied the concept of theory of mind to specific symptoms of schizophrenia, namely delusions of reference, misidentification and persecution, as well as third-person hallucinations. According to Frith, these experiences are by their very nature characterized by a misinterpretation of another person's behaviour or intentions. Whereas autistic children may never develop mentalizing ability, patients with schizophrenia may lose an ability they once had (Frith and Corcoran, 1996).

In a series of experiments, Frith and his co-workers were able to demonstrate impaired theory of mind in subgroups of patients with schizophrenia on a number of newly devised tasks (Corcoran et al., 1995, 1997; Doody et al., 1998; Frith and Corcoran, 1996). Patients with behavioural signs (i.e., negative symptoms and disorganization) and those with paranoid delusions had problems on a hinting task that requires the ability to infer intentions behind indirect speech, in contrast to patients with passivity experiences and patients in remission, who performed normally (Corcoran et al., 1995). A similar pattern of results was found in a subsequent study using stories that involved false beliefs, so that to understand the stories subjects had to infer the mental states of the characters (Frith and Corcoran, 1996). Again, patients with behavioural signs and those with paranoid delusions were impaired on this task, while patients with passivity experiences and those in remission did not differ from normal controls. There were no differences in IQ score between the patients with paranoid delusions and those with passivity experiences or remitted patients, making it unlikely that the observed differences in theory of mind ability could be ascribed to general cognitive impairment. In contrast, the poor performance of patients with behavioural signs was mediated by 
their poor general cognitive abilities. Another study indicated that impaired performance on theory of mind tasks is found in patients with schizophrenia, but not in patients with affective disorders with psychotic symptoms (Doody et al., 1998). Although these studies confirmed the initial hypothesis that impaired theory of mind is associated with specific symptoms, evidence from other studies is mixed. Using a series of comic strips, Sarfati and colleagues found that only patients with thought disorganization had difficulties interpreting the behaviour of the characters (Sarfati and Hardy Bayle, 1999; Sarfati et al., 1997), independent of the mode of presentation, verbal or pictorial (Sarfati et al., 1999). A study by another group included three groups: patients with schizophrenia, patients with depression and deluded patients with psychotic disorders other than schizophrenia (Drury et al., 1998). Patients were investigated during the acute phase and following recovery. In line with the hypothesis, patients with schizophrenia displayed impaired theory of mind abilities compared to nonschizophrenia patients, during psychosis but not following recovery. However, more subtle theory of mind tasks, like the interpretation of irony, failed to distinguish between the groups, which is difficult to reconcile with Frith's account. Furthermore, there were no differences in performance between patients with delusions of reference and persecution, and non-deluded patients, a finding not in line with the notion that impaired theory of mind is the critical mechanism underlying these delusions.

Taken together, the findings indicate that patients with schizophrenia certainly have difficulties performing theory of mind tasks. These difficulties are state rather than trait variables. The impairments seem to be particularly pronounced in patients with negative symptoms or positive behavioural signs, while the predicted association with delusions has been found in some studies. General cognitive abilities seem to mediate only part of the associations between symptoms of schizophrenia and theory of mind abilities.

\section{Source Monitoring}

Source monitoring refers to the processes involved in making attributions about the origin of memories, knowledge and beliefs (Johnson et al., 1993). This decision-making process can apply to various types of distinctions, namely between memories of internally generated information and externally derived information, for example memories for imagination versus memories for perceived events ('reality monitoring'), or between different external sources ('external source monitoring') or between internally generated sources, for example memories of what one said versus memories of what one thought ('internal source monitoring') (Johnson et al., 1993). The notion of reality monitoring may be particularly relevant to psychosis. The nature of several symptoms of psychosis suggests that patients with this disorder are unable to monitor the generation of their own thoughts and actions, which then results in their conclusion that these thoughts or actions came from an external source (Bentall, 1990; Frith, 1992). This may apply to hallucinations, thought insertion, made feelings and other experiences of alien control (Frith, 1992).

\section{Action Monitoring}

A number of studies have applied source-monitoring paradigms to schizophrenia. These paradigms have mainly focused on verbal monitoring (for example, (Bentall et al., 1991; Brébion et al., 1997; Johns et al., 2001), whereas some have investigated the monitoring of actions (Franck et al., 2001; Frith and Done, 1989; Mlakar et al., 1994; Stirling et al., 1998). Studies of action monitoring performance have mainly used tasks that require subjects to keep track of the actions they had just performed in the absence of visual feedback (Frith and Done, 1989; Mlakar et al., 1994; Stirling et al., 1998). The results of these three studies have supported the hypothesis that patients with experiences of alien control have difficulties monitoring their actions internally, particularly when the actions are self-generated rather than being directed by external stimuli. In the study by Franck et al. (2001) visual feedback was not absent but distorted. The image of a virtual hand was superimposed on a subject's real hand holding a joystick, so that the subject only saw the virtual hand. Subjects executed discrete movements, while angular biases and temporal delays were randomly introduced in some trials. The task was to decide immediately after each trial whether the movement they saw corresponded exactly to the one they made with there own hand. In the trials with angular biases patients with delusions of influence made more errors than controls and non-influenced patients with schizophrenia. This result suggests that a difficulty in keeping track of one's own actions is a critical mechanism underlying delusions of influence.

\section{Verbal Monitoring}

In the verbal monitoring paradigm developed by Johnson et al. (1981), subjects are required to generate answers to clues, consisting of a category and a letter, and to listen to paired associates consisting of a category and a particular. To manipulate the amount of cognitive effort involved, half of the items were easy clues or high-probability associations (e.g., 'Think of a type of dwelling beginning with H...', 'A type of footwear - shoe') and half were difficult clues or low-probability associations (e.g., "Think of a fruit beginning with T...', 'A country - Norway'). In normals, confusion between memories of perceived and imagined events increases with decreases in the amount of cognitive effort that is associated with the self-generated event (Johnson et al., 1981). After 1 week, subjects are presented a list in which their answers to the clues are mixed with the associates and with words not previously presented. Their task was to identify the source of each item on the list. Bentall et al. (1991) used this task to compare performance between three groups: patients with schizophrenia who were currently hallucinating, patients with delusions but no history of hallucinations, diagnosed with schizophrenia or delusional disorder, and normal controls. Both patient groups were less accurate on the source-monitoring task compared to controls. A specific bias was present in the patients with hallucinations: they more often misattributed self-generated answers to the experimenter than either the psychiatric or the healthy controls, a difference that was significant for the items that required high cognitive effort. Using a similar paradigm, another study also reported a bias toward attributing self-generated items to an external source (Brébion et al., 1997). Keefe et al. applied multinomial modelling analysis to source-monitoring data, a method that yields separate and independent measures of recognizing information, remembering its source and response biases (Keefe et al., 1999a). This analysis indicated that patients were impaired in reality monitoring, as well as internal and external monitoring. In case of ambiguity, when someone did not remember the source of the information, patients with schizophrenia showed a stronger bias than controls to report that it came from an external source.

\section{Online Monitoring}

The tasks used in the studies described so far require subjects to identify the source of events some time after they had been presented or generated. Johns et al. (2001) developed a paradigm that involves immediate monitoring, which might be more relevant to the mechanisms underlying the psychotic symptoms. Participants read single words aloud while they received feedback of their own voice or alien feedback (someone else's voice). In some trials, the acoustic characteristics of the speech were distorted. Immediately 
after reading aloud the words, subjects had to identify the source of the speech they heard. Both patients with hallucinations and delusions and patients with delusions but no hallucinations made more errors than the control group when reading aloud with distorted feedback of their own voice. The patients with hallucinations had the strongest tendency to misattribute their distorted voice to someone else, particularly when the words presented had a negative emotional content.

Bentall (1990) has argued that the misattribution may be influenced by top-down processes, such as beliefs and expectations about the self and the world. This cognitive bias may operate in addition to deficits in discriminating between external and internal events. The bias may be reinforced by the anxiety reduction that is associated with attributing negative thoughts to an external source. The results reported by Morrison and Haddock (1997) supported the role of a cognitive bias. Subjects rated their response on a word association task in terms of how much a self-generated thought was their own. Patients with hallucinations had lower internality rating than both the psychiatric and the normal control group, particularly with emotional material. A subsequent study indicated that these internality ratings were associated with metacognitive beliefs about uncontrollability and danger (Baker and Morrison, 1998).

In sum, a number of studies have documented robust deficits of reality monitoring in schizophrenia, with a tendency to attribute events to an external source in case of ambiguity. Other forms of source monitoring, namely internal and external monitoring, may be impaired as well. The results of different studies are not entirely consistent regarding the associations with specific symptoms of psychosis. In general, if a relation between impaired source monitoring and symptoms is found, it is mainly with symptoms of alien control rather than hallucinations per se. However, the presence of an external attribution bias may be specifically involved in hallucinations.

\section{COGNITIVE DEFICITS AS VULNERABILITY FACTORS}

Deficits in specific functions, like source monitoring and theory of mind, are most likely state-dependent variables. However, this is certainly not the case for all cognitive deficits in schizophrenia. Strong evidence for trait-like deficits comes from studies involving non-psychotic individuals with a genetically mediated vulnerability to schizophrenia. According to the vulnerability/stress model, some individuals have a predisposition to schizophrenia that is largely determined by genetic and neurodevelopmental factors (Nuechterlein and Dawson, 1984; Zubin and Spring, 1977). Many studies have attempted to find markers of this vulnerability in first-degree adult relatives of patients with schizophrenia and in individuals with a higher risk of developing schizophrenia than the general population.

\section{Cognitive Deficits in Non-Psychotic Relatives}

\section{Adult Relatives}

Several studies have suggested that adult relatives of patients with schizophrenia have mild cognitive impairments (Faraone et al., 1995, 1999; Krabbendam et al., 2001; see Kremen et al., 1994, for a review). The study by Krabbendam et al. (2001) suggested that the pattern of deficits in relatives is similar, albeit milder, to that found in patients. They found that for both patients and relatives attention, verbal memory and working memory independently discriminated from control performance, with a similar pattern in the order of the effects. A 4-year follow-up study by Faraone and colleagues indicated that the neuropsychological deficits in the non-psychotic relatives are stable over time (Faraone et al., 1995, 1999). In a subsequent study, these authors demonstrated that non-psychotic individuals with two first-degree relatives with schizophrenia have lower estimated intelligence and worse performance on visual and verbal memory, compared to persons with only one firstdegree relative with schizophrenia. Thus, the cognitive deficits in the relatives reflect their degree of genetic predisposition to schizophrenia.

A likely explanation for the cognitive deficits in non-psychotic adult relatives is that the deficits are transmitted within families of patients with schizophrenia, as markers of genetic risk. If this is the case, specific cognitive deficits may possibly be used as intermediate phenotypes to facilitate genetic studies of schizophrenia (Egan et al., 2000; Tsuang, 1993). The advantage of this approach compared to using the schizophrenia diagnosis as the phenotype is that it may be possible to identify subgroups that are genetically more homogeneous. Further, the intermediate phenotypes may have a simpler genetic architecture. To assess whether cognitive deficits are useful as phenotypes for genetic studies, one needs to examine heritability estimates. Only few studies have done this. Chen et al. (1998) found very high relative risk for sustained attention in a Taiwanese cohort, which suggests that this phenotype is highly heritable. In the study by Egan and colleagues, relative risk of impaired sustained attention was in the moderate range (Egan et al., 2000). Although it is too early to conclude that cognitive deficits can be used as phenotypic markers, these findings at least suggest that it would be useful to explore this possibility further.

This, however, does not mean that cognitive deficits in schizophrenia cannot be due to environmental mechanisms. Specifically, obstetric complications may be associated with schizophrenia (Dalman et al., 1999) as well as with compromised intellectual development (Aylward et al., 1989). In the study reported by Gilvarry and colleagues $(2000,2001)$, relatives of patients who have been exposed to obstetric complications performed significantly better on measures of IQ and verbal fluency than did relatives of patients not exposed to obstetric complications. This suggests that impaired IQ and verbal fluency were not transmitted in the families of the patients with a history of obstetric complications, but were a consequence of the patient's exposure to obstetric complications.

\section{Children of Patients with Schizophrenia}

The high-risk research typically involves children of a parent with schizophrenia, assessed during childhood and adolescence. A number of studies have suggested that offspring of patients with schizophrenia may display impairments in attention skills (Hans et al., 1999; Mirsky et al., 1995a), executive functions, memory and intellectual function (Byrne et al., 1999). Unlike the adult relatives, children of patients with schizophrenia form a heterogeneous group, because some of the children will eventually develop schizophrenia themselves and others will not. Long periods of follow-up have been performed to identify the factors that are associated with later development of schizophrenia (ErlenmeyerKimling et al., 1993; Mirsky et al., 1995b). The NIMH-Israeli High-Risk Study conducted a long-term follow-up of children having a parent with schizophrenia (Mirsky et al., 1995b). One hundred children were originally included, 50 of them having a parent with schizophrenia, and 50 control children. Cognitive assessments were conducted at ages 11, 17, 26 and 32. Sixty-three subjects could be included in the last assessment. The children who eventually developed schizophrenia spectrum disorders, including schizophrenia, were identifiable by attentional deficits at age 11. Results of the New York High-Risk Project have indicated that childhood deficits in attention, verbal memory and gross motor skills distinguish children who develop schizophrenia-related psychoses in adulthood from children at risk for schizophrenia who did not develop schizophrenia-related psychoses in adulthood 
(Cornblatt et al., 1999; Erlenmeyer-Kimling et al., 2000). In this project, the offspring of patients with schizophrenia were tested neuropsychologically and behaviourally at 7-12 years of age and assessed again in mid-adulthood for psychiatric diagnoses. In sum, several cognitive abnormalities, notably attentional deficits, are present in offspring of patients with schizophrenia, particularly in those children who eventually develop schizophrenia spectrum disorders themselves.

Several population-based studies of IQ and later development of schizophrenia have been conducted (e.g., David et al., 1997; Jones et al., 1994a, 1994b). These studies have indicated that low IQ in childhood or young adolescence is a risk factor for subsequent development of schizophrenia. Based on a 19-year longitudinal study of a community sample, Kremen and colleagues have reported that an unexpected drop in IQ between the ages of 4 and 7 was strongly and independently associated with later psychotic symptoms (Kremen et al., 1998). Two possible mechanisms may account for the relation between childhood IQ and schizophrenia. IQ could be indirectly associated with schizophrenia, with any factors causing lower IQ, such as genetic predisposition or abnormal brain development, increasing the risk for schizophrenia. Alternatively, the association could be causal, with low IQ reducing the capacity to cope with stressors or leading to false beliefs and perceptions.

\section{Cognitive Deficits in Schizotypy}

An alternative approach to identify factors associated with schizophrenia liability has been to study schizotypic subjects, either individuals diagnosed with DSM-IV schizotypal personality disorder, or individuals who display deviance on psychometric tests for schizotypy ('psychosis proneness'). This approach starts from the assumption that schizophrenia is the extreme end of a continuum that ranges from mild to severe, with schizotypy being part of this continuum (Claridge, 1994). Family studies have reported elevated rates of schizotypy in relatives of patients with schizophrenia, indicating that schizotypy shares a common genetic vulnerability to schizophrenia (Kendler et al., 1993, 1994). To the extent that this is the case, schizotypal subjects may have the same pattern of cognitive deficits as individuals with schizophrenia, albeit to a lesser degree.

Based on studies involving either subjects with schizotypal personality disorder (Cadenhead et al., 1999; Diforio et al., 2000; Trestman et al., 1995; Voglmaier et al., 1997, 2000) or psychometrically identified 'psychosis-prone' subjects (Lenzenweger and Gold, 2000; Lenzenweger and Korfine, 1994; Park et al., 1995), findings have indeed supported the notion of a shared cognitive liability. Cadenhead and co-workers (1999) reported widespread deficits in 20 subjects with schizotypal personality disorder, including deficits of attention, verbal working memory, abstract reasoning and general intellectual functioning. The deficits were of lesser magnitude than those observed in the patients with schizophrenia. Deficits of executive functions were found in adolescents with schizotypal personality disorder, particularly in individuals with negative symptoms (Diforio et al., 2000). However, the deficits were only apparent on one test of executive function, the Modified WCST, and not on the Tower of London or verbal fluency tests, which may reflect that these tests may not be sensitive enough to detect the mild cognitive impairments in schizotypal personality disorder. In a comparison of undergraduate students who scored high and low, respectively, on the Perceptual Aberration Scale (Chapman et al., 1978), high scores were associated with deficits of visuospatial working memory (Park et al., 1995), but not auditory working memory (Lenzenweger and Gold, 2000). This latter finding was somewhat unexpected, given that auditory working memory is impaired in patients with schizophrenia (Aleman et al., 1999; Gold et al., 1997) and that the modal finding in schizotypy research is that the cognitive profile of schizotypic individuals resembles that of patients, although in attenuated form. According to the authors, one possible explanation for this result could be that the task used to assess auditory working memory (namely, letter-number span) involved discrete trials and so did not require subjects to hold online the information over a delay period, in contrast to the task used to assess visuospatial working memory.

Some studies have explored the notion of reduced cognitive inhibition in schizotypy (Beech et al., 1991; Moritz and Mass, 1997; Peters et al., 1994; Williams, 1995). Cognitive inhibition refers to the active suppression of irrelevant information, one of the functions of the context module in the computational model by Cohen and Servan-Schreiber described above (Cohen et al., 1999; Cohen and Servan-Schreiber, 1992). These studies have used a negative priming paradigm (Tipper, 1985), which typically consists of a target word presented subsequently to a semantically related, or identical, ignored distractor word. Negative priming refers to the longer reaction times following the ignored distractor word, a phenomenon that is thought to reflect reduced inhibition. The findings converge on the point that every study reported increased negative priming, particularly in those subjects who scored high on the scales for positive schizotypal symptoms.

\section{FUNCTIONAL CONSEQUENCES AND TREATMENT ISSUES}

\section{Impact of Cognitive Deficits on Daily Functioning}

Given the scope of the cognitive impairment in schizophrenia, an important question is in what way this impairment affects daily functioning. Despite its clinical relevance, this question has been largely ignored until roughly a decade ago. Nevertheless, some trends emerge from the available empirical data.

In a review of 17 studies, Green (1996) divided the literature into three areas of functional outcome, namely community outcome, social problem solving and skill acquisition. Measures of community outcome included assessments of occupational functioning, quality of social networks and degree of independent living. Although there were large differences between studies with regard to cognitive as well as outcome measures, a replicated finding was that baseline verbal episodic memory and executive functions, assessed with the WCST, predicted community functioning at follow-up (Green, 1996; Velligan et al., 2000). Social problem solving is considered to be a component of community functioning. Most studies have assessed social problem solving using laboratory measures that presents the subjects with videotaped vignettes depicting an interpersonal problem (e.g., a waitress writing down an order incorrectly; Donahoe et al., 1990). The task of the subject is to describe the problem, to derive a solution and to enact this solution in a role-played simulation. Despite some variety between studies in the selection of the outcome measures, a consistent finding was that both verbal memory and vigilance, or sustained attention, were related to social problem solving, whereas executive functions were not (Green, 1996). The majority of the studies in the review were cross-sectional. Subsequent 2-year longitudinal studies of cognitive functioning and social problem solving have reported that both predictive ability of baseline cognitive functions (Addington and Addington, 2000) and the level of social functioning (Dickerson et al., 1999) are stable over time.

Acquisition of psychosocial skills is another determinant of community functioning. Rehabilitation programmes involve skill acquisition, as these programmes instruct patients with regard to interpersonal skills, leisure activities and vocational skills. Studies that have investigated the relation between cognitive functions and skill acquisition have generally assessed cognition at baseline and progress of psychosocial skills during the course of a rehabilitation 
programme (Green, 1996). Verbal memory was associated with skill acquisition, as it was with community functioning and social problem solving. Also, verbal working memory and vigilance were associated with skill acquisition. Executive functions did not consistently predict success of rehabilitation programmes.

This summary of findings suggests some specificity in the associations between cognitive functions and outcome. Some of the observed relations have clear face validity, for example, the finding that verbal memory predicts skill acquisition. Yet, it should be noted that the absence of relations between other cognitive functions and outcome might as well have resulted from lack of power due to small sample sizes. In fact, Velligan and colleagues (2000) found evidence for many other associations between cognitive functions and community functions. According to these authors, the multitude of associations may be due to the fact that both cognitive test performance and functional skills do not involve isolated abilities, but instead are determined by several cognitive abilities.

Eight studies that were included in the review by Green (1996) evaluated the relationship between psychotic symptoms and functional outcome. None of them reported a significant relation. However, these studies used composite measures of psychotic symptoms, and so the possibility remains that negative effects of single symptoms, for example thought disorder, were obscured. Negative symptoms showed replicated links with social problem solving, but not with skill acquisition, whereas relations with community functioning were inconsistent. According to the path model by Velligan and colleagues (1997; see also Green, 1998), the pattern of associations between symptoms, cognitive functions and functional outcome suggests that cognitive functions mediate the relation between negative symptoms and outcome. That is, when cognitive impairment is used to predict functional outcome, the contribution of negative symptoms to the prediction is very much reduced. This emphasizes the necessity of addressing cognitive impairments in pharmaceutical or psychosocial interventions.

\section{Effect of Medication on Cognitive Functions}

\section{Conventional Antipsychotics}

The therapeutic effects of conventional antipsychotic drugs are largely confined to the positive symptoms. These drugs were not designed to improve cognitive functions. Given their impact on several neurotransmitter systems that are implicated in arousal, attention as well as other cognitive functions, it is likely that they do influence cognition, either positively or negatively. Studies involving healthy volunteers have yielded evidence for negative effects, particularly for medication with sedating effects, such as thioridazine (Hindmarch and Tiplady, 1994; King, 1994). In patients, investigating the effects of antipsychotic medication on cognition is hindered by methodological and ethical concerns. For example, discontinuation or delay of drug treatment to study the course of cognitive functioning is often not advisable. Nevertheless, several reviews have concluded that the deleterious effects of antipsychotic medication on cognitive functioning in patients are only minor (Medalia et al., 1988; Spohn and Strauss, 1989). For example, neuroleptically naive patients with schizophrenia had a similar pattern of cognitive deficits as did previously treated patients (Saykin et al., 1994). In another study, a substantial dose reduction of conventional antipsychotic medication did not have marked effects on cognitive functioning (Seidman et al., 1993). There may even be a slight beneficial effect of antipsychotic medication on cognition (Spohn and Strauss, 1989; Verdoux et al., 1995).

There is one possible exception to this, namely the effect of anticholinergic medication or of the anticholinergic properties of antipsychotic drugs. Anticholinergics are known to impair memory and it seems plausible that this effect could contribute to the memory impairment seen in patients with schizophrenia (Goldberg et al., 1993a; King, 1990; Spohn and Strauss, 1989) or to the failure of conventional antipsychotics to improve memory performance in schizophrenia (Mortimer, 1997).

\section{Atypical Antipsychotics}

With the development of atypical antipsychotic medication, such as clozapine, risperidone and olanzapine, the treatment of cognitive dysfunctions has become an important focus. Do these drugs really improve cognition? Keefe et al. (1999b) have recently performed a quantitative analysis of 15 efficacy studies, studying the effects of clozapine (10), risperidone (4), zotepine (1), ziprasidone (1) and aripiprazole (1). The authors first developed methodological standards against which studies in these area may be judged. None of the included study met all methodological requirements; for example, only three studies were double-blind whereas 12 studies were open-label studies. Despite these methodological concerns, the authors felt sufficiently confident to conclude that atypical antipsychotic drugs improve cognitive functioning in schizophrenia, when compared to conventional antipsychotics. Verbal fluency, digit-symbol substitution, fine motor function and executive functions were the strongest responders to the novel antipsychotics. Yet, even on these tests, performance of the patients with schizophrenia did not reach normal levels in any of the studies reviewed. This emphasizes the necessity to investigate the usefulness of cognitionenhancing drugs in schizophrenia, such as those that activate certain dopaminergic receptors or cholinomimetic drugs that increase cortical cholinergic activity (Friedman et al., 1999b).

\section{Cognitive Remediation}

Until a few years ago, there had been little research on cognitive remediation in schizophrenia, despite the fact that it has been established for decades that cognitive deficits persist even after the psychosis subsides. However, the cognitive deficits are now viewed as having direct implications for treatment and findings in the area of neuropsychological interventions are emerging rapidly (Green and Nuechterlein, 1999).

The interventions can take many forms, but generally involve laboratory-based exercises that are related to the cognitive process being trained. Some training programmes use cognitive rehabilitation software. For example, Medalia et al. used a software program entitled 'Where in the USA is Carmen Sandiego?' to remediate problem-solving skills in patients with schizophrenia (Medalia et al., 2001). The purpose of this task was to solve a simulated detective case by interpreting information given to identify the suspect in order to make an arrest. Some studies focus on single tasks, for example, the WCST, to investigate whether performance can be enhanced by inducing specific task modifications, such as reinforcement or feedback (Goldberg and Weinberger, 1994; Green et al., 1992; Hellman et al., 1998). There are large differences between training programmes regarding the intensity and duration of the training. For example, Bell and colleagues (2001) applied neurocognitive enhancement therapy, in which every participant receives feedback about his or her cognitive functioning on a biweekly schedule, as well as cognitive exercises for up to 5 hours each week for 26 weeks and a weekly social processing group. In contrast, the computer-aided training by Medalia et al. $(2000,2001)$ consisted of 10 sessions of 25 minutes, twice weekly for 5 weeks.

Despite the growing literature, there is a paucity of controlled studies. In a recent systematic review by the Cochrane group, only three studies could be included that used a randomized design in which the impact of cognitive rehabilitation on people with schizophrenia was compared to a placebo intervention, another intervention or standard treatment (Hayes and McGrath, 2000). 
This review did not include comparisons of different types of cognitive rehabilitation. Suslow and colleagues (2001) identified nine peer-reviewed studies of attention training in schizophrenia, which incorporated a control group and used external measures of outcome. Both reviews concluded that data are inconclusive and provide no evidence for or against cognitive remediation or attention training in schizophrenia. An important issue is the generalizability of the improvement. Performance on the training task can often be improved (Green et al., 1992; Hellman et al., 1998) but it is doubtful whether these effects generalize meaningfully (Bellack et al., 1996).

Among the few methodologically adequate studies are the study by Wykes and colleagues (1999) and the one by Medalia and colleagues $(2000,2001)$. The study by Wykes et al. (1999) investigated the effects of an intensive cognitive rehabilitation programme. The intervention was targetted at deficits of executive functions, based on procedural learning and the principles of errorless learning, targetted reinforcement and massed practice. It consisted of individual daily sessions of 1 hour for up to 3 months. The control therapy was occupational therapy, matched for length of treatment and therapist contact. Seventeen patients received the cognitive treatment and 16 received occupational therapy. Some improvement in cognition followed both therapies, but the cognitive intervention was superior to the occupational therapy with regard to tests of cognitive flexibility and memory. There were no systematic changes in symptoms or social functioning in either group, with one exception: patients in the cognitive treatment showed a significant increase in self-esteem. The study by Medalia et al. $(2000,2001)$ applied computer-aided training programmes to remediate memory and problem-solving deficits. A sample of 54 patients with schizophrenia were randomly assigned to a memorytraining group, a problem-solving group or a control group. Both training groups received 10 sessions of computer training. The control group participated in routine unit activities. The memorytraining group improved on the training tasks during the course of the training, but they did not make greater gains on external outcome measures of memory. The subjects failed to apply the mnemonic strategies that they learned successfully within training tasks to other general measures of memory and learning. In contrast, the problem-solving group showed a significant improvement on the outcome measure that assessed problem-solving skills required for independent living, an effect that was not present in the other two groups. The authors concluded that patients with schizophrenia are responsive to problem-solving training techniques.

\section{THE CONTRIBUTION OF CLINICAL NEUROPSYCHOLOGY}

The cognitive profile in schizophrenia is characterized by a broad range of deficits. However, there is no single deficit with sufficient specificity to be useful as a diagnostic instrument. Deficits of attention, memory and executive functions may also be present in other psychiatric conditions, such as unipolar or bipolar depression, although in schizophrenia deficits are generally more severe compared to other psychiatric disorders (Martinez Aran et al., 2000; Zakzanis et al., 1999). Furthermore, test results of a patient with schizophrenia may be indistinguishable from those obtained in neurological disorders, such as mild traumatic brain injury (Zakzanis et al., 1999). Therefore, the clinical neuropsychologist cannot rely on quantitative neuropsychological profiles to differentiate schizophrenia and a neurological condition. At the same time, no single test completely discriminates patients with schizophrenia from healthy controls. According to the quantitative review by Zakzanis et al. (1999), the effects of the cognitive variables are associated with a 30-40\% overlap between schizophrenia and control distributions. Indeed, substantial numbers of patients with schizophrenia have normal neuropsychological profiles (Palmer et al., 1997). Thus, cognitive deficit is not an inclusive feature of the illness. In sum, neuropsychological test profiles are of limited use in differential diagnosis and can only be interpreted in the context of qualitative aspects of the assessment as well as information about psychopathology, course of the deficits and premorbid functioning.

Same performance on a test does not necessarily point to the same underlying dysfunction (Keefe, 1995). Patients with schizophrenia may perform poorly for reasons that involve other cognitive and brain processes than patients with neurological disorder. Moreover, clinical neuropsychological tests were designed to be sensitive to the type of dysfunction seen with brain lesions. These tests are sensitive to a range of cognitive deficits in schizophrenia as well, but they do not tell us much about the origins of the characteristic symptoms of this disorder. Perhaps the current neuropsychological instrumentarium should be supplemented with tests that fit the psychopathology in schizophrenia, for example tests involving source monitoring or theory of mind. This may give clues to the cognitive mechanisms that may be involved in vulnerability for psychosis.

Clinical neuropsychological assessment does contribute to individual health care, but this contribution most likely concerns treatment and prognosis rather than psychiatric diagnosis. Deficits of attention, memory and executive functions predict functional outcome, possibly even more so than the psychotic symptoms do (Green, 1996; Velligan et al., 2000; see 'Impact of cognitive deficits on daily functioning', above). Thus, the cognitive assessment can be used to adjust the rehabilitation programme to the strengths and weaknesses of the individual patient.

\section{CONCLUDING REMARKS}

The cognitive profile in schizophrenia is characterized by deficits across several domains, notably attention, memory and executive functions. The attentional deficits include sustained attention, the capacity to maintain a state of readiness to respond to small changes in the environment, as well as selective attention: the capacity to focus while ignoring irrelevant information. Memory functions that are particularly affected include verbal memory and learning, working memory and semantic memory. The aspects of executive functions that are compromised in schizophrenia are the capacities for volitional activity, forward planning and selfregulation. Regarding the course of the deficits, the evidence is mostly in favour of a relatively stable course, with no further deterioration once the deficits have been established during the first few years following the onset of the first psychotic episode.

An issue that continues to raise considerable debate is whether the cognitive deficit in schizophrenia can best be characterized in terms of a generalized or a specific impairment. Studies that attempt to resolve this issue have to deal with the methodological problems associated with measuring a differential deficit against a background of general impairment, that is, a deficit that is more pronounced than any other cognitive deficit. Given the psychometric limitations of the currently availably cognitive tests, findings of both generalized and specific deficits must be interpreted with caution.

A related issue is whether a single mechanism can be found that can account for the range of deficits in schizophrenia. An influential hypothesis is that a single deficit in the processing of context is sufficient to produce all cognitive deficits as well as certain symptoms of schizophrenia. Strong support for this hypothesis has come from computer models. It appeared from these models that the pervasive deficit seen in schizophrenia could be simulated by disturbance of a single context module that carried out the maintenance of information and the inhibition of irrelevant information. 
The psychopathology in schizophrenia is notoriously diverse. Several classifications have been proposed, either categorical or dimensional, and numerous studies have tried to identify distinct cognitive profiles associated with these subtypings. This correlational approach has yielded some interesting results, although typically associations between symptoms and neurocognitive deficits are only modest. An alternative approach to the relation between symptoms and cognition has been to test cognitive models of individual symptoms. Two paradigms that have received substantial empirical support are theory of mind and reality monitoring, in relation to delusions and hallucinations respectively. Impairments of theory of mind seem to be particularly pronounced in patients with negative symptoms or positive behavioural signs, while the predicted association with delusions has been found in some studies. A number of studies have documented robust deficits of reality monitoring in schizophrenia, with a tendency to attribute events to an external source in case of ambiguity. Other forms of monitoring may also be impaired. In general, if a relationship between impaired reality monitoring and symptoms is found, it is mainly with symptoms of alien control rather than hallucinations per se. However, the presence of an external attribution bias may be specifically involved in hallucinations.

While the symptom approach tries to identify those cognitive abnormalities that may underlie specific symptoms of psychosis, the focus of the vulnerability approach is on cognitive deficits that have a trait character, independent of the symptoms. According to the vulnerability/stress model, some individuals have a predisposition to schizophrenia that is largely determined by genetic and neurodevelopmental factors. Studies have attempted to find markers of this vulnerability in first-degree adult relatives of patients with schizophrenia and in individuals with a higher risk of developing schizophrenia than the general population. It appeared from this research that cognitive deficits are robust markers of schizophrenia vulnerability, although further research should investigate whether they are useful as alternative phenotypes in genetic studies.

Although the functional relevance of the cognitive deficits in schizophrenia has not received much attention, the available data suggest that deficits of verbal episodic memory, vigilance and executive functions influence functional outcome. Deficits in these, and presumably other domains of cognitive functioning restrict the possibilities for functional recovery, possibly even more so than do the symptoms of psychosis. This indicates that successful treatment goes beyond the reduction of the symptoms of psychosis. Cognitive deficits should be a target for intervention, whether pharmaceutically or psychologically. The therapeutic effects of conventional antipsychotic medication on cognition are generally considered to be minor. There is some evidence that atypical antipsychotic drugs improve cognitive functioning in schizophrenia, when compared to conventional antipsychotics. Yet, in none of the empirical studies does performance of patients with schizophrenia reach normal levels. This emphasizes the necessity to investigate the usefulness of cognition-enhancing drugs in schizophrenia. Few studies have been conducted that examine the effects of cognitive remediation on cognitive and daily functioning in schizophrenia in a controlled design. Therefore, there is as yet no evidence for or against cognitive remediation as a treatment in schizophrenia. However, given the impact of cognitive deficits on functioning in schizophrenia, the field invites exploration.

\section{REFERENCES}

Addtington, J. and Addington, D., 1997. Attentional vulnerability indicators in schizophrenia and bipolar disorder. Schizophrenia Research, 23 $197-204$.

Addington, J. and Addington, D., 2000. Neurocognitive and social functioning in schizophrenia: a 2.5 year follow-up study. Schizophrenia Research, 44, 47-56
Aleman, A., Hijman, R., De Haan, E.H.F. and Kahn, R.S., 1999. Memory impairment in schizophrenia: a meta-analysis. American Journal of Psychiatry, 156, 1358-1366.

Arndt, S., Andreasen, N.C., Flaum, M., Miller, D. and Nopoulos, P., 1995. A longitudinal study of symptom dimensions in schizophrenia: prediction and patterns of change. Archives of General Psychiatry, 52, $352-360$.

Aylward, E., Walker, E. and Bettes, B., 1984. Intelligence in schizophrenia: meta-analysis of the research. Schizophrenia Bulletin, 10, 430-459.

Aylward, G.P., Pfeiffer, S.L., Wright, A. and Verhulst, S.J., 1989. Outcome of studies of low birth weight infants published in the last decade: a meta-analysis. Journal of Pediatrics, 115, 515-520.

Baddeley, A. and Hitch, G., 1974. Working memory. In: Bower, G.A. (ed.), Psychology of Learning and Motivation, Vol. 8, pp. 47-89. Academic Press, New York.

Baddeley, A. and Hitch, G., 1994. Developments in the concept of working memory. Special section: Working memory. Neuropsychology, 8, $485-493$.

Baker, C.A. and Morrison, A.P., 1998. Cognitive processes in auditory hallucinations: attributional biases and metacognition. Psychological Medicine, 28, 1199-1208.

Barch, D.M. and Carter, C.S., 1998. Selective attention in schizophrenia: relationship to verbal working memory. Schizophrenia Research, 33, 53-61.

Barch, D.M., Carter, C.S., Hachten, P.C., Usher, M. and Cohen, J.D., 1999. The 'benefits' of distractibility: mechanisms underlying increased Stroop effects in schizophrenia. Schizophrenia Bulletin, 25, 749-762.

Baron-Cohen, S., Leslie, A.M. and Frith, U., 1985. Does the autistic child have a 'theory of mind'? Cognition, 21, 37-46.

Baruch, J., Hemsley, D.R. and Gray, J.A., 1988. Differential performance of acute and chronic schizophrenics in a latent inhibition task. Journal of Nervous and Mental Disease, 176, 598-606.

Beatty, W.W., Jocic, Z., Monson, N. and Staton, R.D., 1993. Memory and frontal lobe dysfunction in schizophrenia and schizoaffective disorder. Journal of Nervous and Mental Disease, 181, 448-453.

Beech, A., McManus, D., Baylis, G., Tipper, S. and Agar, K., 1991. Individual differences in cognitive processes: towards an explanation of schizophrenic symptomatology. British Journal of Psychology, 82, 417-426.

Bell, M., Bryson, G., Greig, T., Corcoran, C. and Wexler, B.E., 2001. Neurocognitive enhancement therapy with work therapy: effects on neuropsychological test performance. Archives of General Psychiatry, 58, $763-768$.

Bellack, A.S., Blanchard, J.J., Murphy, P. and Podell, K., 1996. Generalization effects of training on the Wisconsin Card Sorting Test for schizophrenia patients. Schizophrenia Research, 19, 189-194.

Bellini, L., Abbruzzese, M., Gambini, O., Rossi, A., Stratta, P. and Scarone, S., 1991. Frontal and callosal neuropsychological performances in schizophrenia: further evidence of possible attention and amnesic dysfunctions. Schizophrenia Research, 5, 115-121.

Bentall, R.P., 1990. The illusion of reality: a review and integration of psychological research on hallucinations. Psychological Bulletin, 107, $82-95$.

Bentall, R.P., Baker, G.A. and Havers, S., 1991. Reality monitoring and psychotic hallucinations. British Journal of Clinical Psychology, 30, 213-222.

Berg, E.A., 1948. A simple objective technique for measuring flexibility in thinking. Journal of General Psychology, 39, 15-22.

Berman, I., Viegner, B., Merson, A., Allan, E., Pappas, D. and Green, A.I., 1997. Differential relationships between positive and negative symptoms and neuropsychological deficits in schizophrenia. Schizophrenia Research, 25, 1-10.

Bilder, R.M., Goldman, R.S., Robinson, D. et al., 2000. Neuropsychology of first-episode schizophrenia: initial characterization and clinical correlates. American Journal of Psychiatry, 157, 549-559.

Blanchard, J.J. and Neale, J.M., 1994. The neuropsychological signature of schizophrenia: generalized or differential deficit? American Journal of Psychiatry, 151, 40-48.

Braff, D.L., 1993. Information processing and attention dysfunctions in schizophrenia. Schizophrenia Bulletin, 19, 233-259.

Braff, D.L., Heaton, R., Kuck, J. et al., 1991. The generalized pattern of neuropsychological deficits in outpatients with chronic schizophrenia with heterogeneous Wisconsin Card Sorting Test results. Archives of General Psychiatry, 48, 891-898. 
Brébion, G., Smith, M.J., Gorman, J.M. and Amador, X., 1997. Discrimination accuracy and decision biases in different types of reality monitoring in schizophrenia. Journal of Nervous and Mental Disease, 185, $247-253$.

Brekke, J.S., Raine, A. and Thomson, C., 1995. Cognitive and psychophysiological correlates of positive, negative, and disorganized symptoms in the schizophrenia spectrum. Psychiatry Research, 57, 241-250.

Butler, R.W., Jenkins, M.A., Sprock, J. and Braff, D.L., 1992. Wisconsin Card Sorting Test deficits in chronic paranoid schizophrenia: evidence for a relatively discrete subgroup? Schizophrenia Research, 7 , $169-176$.

Byrne, M., Hodges, A., Grant, E., Owens, D.C. and Johnstone, E.C., 1999. Neuropsychological assessment of young people at high genetic risk for developing schizophrenia compared with controls: preliminary findings of the Edinburgh High Risk Study (EHRS). Psychological Medicine, 29, $1161-1173$.

Cadenhead, K.S., Perry, W., Shafer, K. and Braff, D.L., 1999. Cognitive functions in schizotypal personality disorder. Schizophenia Research, $\mathbf{3 7}$ $123-132$.

Cameron, N., 1939. Schizophrenic thinking in a problem-solving situation. Journal of Mental Science, 85, 1012-1035.

Cannon, T.D., Rosso, I.M., Bearden, C.E., Sanchez, L.E. and Hadley, T., 1999. A prospective cohort study of neurodevelopmental processes in the genesis and epigenesis of schizophrenia. Development and Psychopatholy, 11, 467-485.

Cantor Graae, E., Warkentin, S. and Nilsson, A., 1995. Neuropsychological assessment of schizophrenic patients during a psychotic episode: persistent cognitive deficit? Acta Psychiatrica Scandinavica, 91, 283-288.

Capleton, R.A., 1996. Cognitive function in schizophrenia: association with negative and positive symptoms. Psychological Reports, 78, 123-128.

Carter, C.S., Robertson, L.C. and Nordahl, T.E., 1992. Abnormal processing of irrelevant information in schizophrenia: selective enhancement of Stroop facilitation. Psychiatry Research, 41, 137-146.

Censits, D.M., Ragland, J.D., Gur, R.C. and Gur, R.E., 1997. Neuropsychological evidence supporting a neurodevelopmental model of schizophrenia: a longitudinal study. Schizophrenia Research, 24, 289-298.

Chapman, L.J. and Chapman, J.P., 1978. The measurement of differential deficit. Journal of Psychiatric Research, 14, 303-311.

Chapman, L.J. and Chapman, J.P., 1989. Strategies for resolving the heterogeneity of schizophrenics and their relatives using cognitive measures. Journal of Abnormal Psychology, 98, 357-366.

Chapman, L.J., Chapman, J.P. and Raulin, M.L., 1978. Body-image aberration in schizophrenia. Journal of Abnormal Psychology, 87, 399-407.

Chen, E.Y., Wilkins, A.J. and McKenna, P.J., 1994. Semantic memory is both impaired and anomalous in schizophrenia. Psychological Medicine, 24, 193-202.

Chen, W.J., Liu, S.K., Chang, C.J., Lien, Y.J., Chang, Y.H. and Hwu, H.G., 1998. Sustained attention deficit and schizotypal personality features in nonpsychotic relatives of schizophrenic patients. American Journal of Psychiatry, 155, 1214-1220.

Clare, L., McKenna, P.J., Mortimer, A.M. and Baddeley, A.D., 1993. Memory in schizophrenia: what is impaired and what is preserved? Neuropsychologia, 31, 1225-1241.

Claridge, G., 1994. Single indicator of risk for schizophrenia: probable fact or likely myth? Schizophrenia Bulletin, 20, 151-168.

Cohen, J.D. and Servan-Schreiber, D., 1992. Context, cortex, and dopamine: a connectionist approach to behavior and biology in schizophrenia. Psychology Review, 99, 45-77.

Cohen, J.D. and Servan-Schreiber, D., 1993. A theory of dopamine function and its role in cognitive deficits in schizophrenia. Schizophrenia Bulletin, 19, 85-104.

Cohen, J.D., Barch, D.M., Carter, C. and Servan Schreiber, D., 1999 Context-processing deficits in schizophrenia: converging evidence from three theoretically motivated cognitive tasks. Journal of Abnormal Psychology, 108, 120-133.

Corcoran, R., Mercer, G. and Frith, C.D., 1995. Schizophrenia, symptomatology and social inference: investigating 'theory of mind' in people with schizophrenia. Schizophrenia Research, 17, 5-13.

Corcoran, R., Cahill, C. and Frith, C.D., 1997. The appreciation of visual jokes in people with schizophrenia: a study of 'mentalizing' ability. Schizophrenia Research, 24, 319-327.

Cornblatt, B., Obuchowski, M., Roberts, S., Pollack, S. and ErlenmeyerKimling, L., 1999. Cognitive and behavioral precursors of schizophrenia. Development and Psychopathology, 11, 487-508.
Crawford, J.R., Besson, J.A., Bremner, M., Ebmeier, K.P., Cochrane, R.H. and Kirkwood, K., 1992. Estimation of premorbid intelligence in schizophrenia. British Journal of Psychiatry, 161, 69-74.

Cutting, J. and Murphy, D., 1990. Impaired ability of schizophrenics relative to manics, or depressives, to appreciate social knowledge about their culture. British Journal of Psychiatry, 157, 355-358.

Cutting, J., David, A. and Murphy, D., 1987. The nature of overinclusive thinking in schizophrenia. Psychopathology, 20, 213-219.

Dalman, C., Allebeck, P., Cullberg, J., Grunewald, C. and Köster, M., 1999. Obstetric complications and the risk of schizophrenia. Archives of General Psychiatry, 56, 234-240.

David, A.S., Malmberg, A., Brandt, L., Allebeck, P. and Lewis, G., 1997. IQ and risk for schizophrenia: a population-based cohort study. Psychological Medicine, 27, 1311-1323.

Diamond, M.D., 1956. The ability of schizophrenics to modify responses in an interpersonal situation. Journal of Consulting Psychology, 20, $441-444$.

Dickerson, F., Boronow, J.J., Ringel, N. and Parente, F., 1999. Social functioning and neurocognitive deficits in outpatients with schizophrenia: a 2-year follow-up. Schizophrenia Research, 37, 13-20.

Diforio, D., Walker, E.F. and Kestler, L.P., 2000. Executive functions in adolescents with schizotypal personality disorder. Schizophrenia Research, 42, 125-134.

Donahoe, C.P., Carter, M.J., Bloem, W.D., Hirsch, G.L., Laasi, N. and Wallace, C.J., 1990. Assessment of interpersonal problem solving skills. Psychiatry, 53, 329-339.

Doody, G.A., Gotz, M., Johnstone, E.C., Frith, C.D. and Owens, D.G., 1998. Theory of mind and psychoses. Psychological Medicine, 28, 397-405.

Drury, V.M., Robinson, E.J. and Birchwood, M., 1998. 'Theory of mind' skills during an acute episode of psychosis and following recovery. Psychological Medicine, 28, 1101-1112.

Egan, M.F., Goldberg, T.E., Gscheidle, T., Weirich, M., Bigelow, L.B. and Weinberger, D.R., 2000. Relative risk of attention deficits in siblings of patients with schizophrenia. American Journal of Psychiatry, 157 1309-1316.

Elliot, R., McKenna, P.J., Robbins, T.W. and Sahakian, B.J., 1995. Neuropsychological evidence for frontostriatal dysfunction in schizophrenia. Psychological Medicine, 25, 619-630.

Elvevåg, B., Weinberger, D.R., Suter, J.C. and Goldberg, T.E., 2000. Continuous performance test and schizophrenia: a test of stimulus-response compatibility, working memory, response readiness, or none of the above? American Journal of Psychiatry, 157, 772-780.

Erlenmeyer-Kimling, L., Cornblatt, B.A., Rock, D., Roberts, S., Bell, M and West, A., 1993. The New York High-Risk Project: anhedonia, attentional deviance, and psychopathology. Schizophrenia Bulletin, 19, $141-153$.

Erlenmeyer-Kimling, L., Rock, D., Roberts, S.A. et al., 2000. Attention, memory, and motor skills as childhood predictors of schizophreniarelated psychoses: the New York High-Risk Project. American Journal of Psychiatry, 157, 1416-1422.

Evans, J.J., Chua, S.E., McKenna, P.J. and Wilson, B.A., 1997. Assessment of the dysexecutive syndrome in schizophrenia. Psychological Medicine, 27, 635-646.

Eyler Zorrilla, L.T., Heaton, R.K., McAdams, L.A., Zisook, S., Harris, M.J. and Jeste, D.V., 2000. Cross-sectional study of older outpatients with schizophrenia and healthy comparison subjects: no differences in age-related cognitive decline. American Journal of Psychiatry, 157, 1324-1326.

Faraone, S.V., Seidman, L.J., Kremen, W.S., Pepple, J.R., Lyons, M.J. and Tsuang, M.T., 1995. Neuropsychological functioning among the nonpsychotic relatives of schizophrenic patients: a diagnostic efficiency analysis. Journal of Abnormal Psychology, 104, 286-304.

Faraone, S.V., Seidman, L.J., Kremen, W.S., Toomey, R., Pepple, J.R. and Tsuang, M.T., 1999. Neuropsychological functioning among the nonpsychotic relatives of schizophrenic patients: a 4-year follow-up study. Journal of Abnormal Psychology, 108, 176-181.

Fleming, K., Goldberg, T.E. and Gold, J.M., 1994. Applying working memory constructs to schizophrenic impairment. In: David, A.S. and Cutting, J.C. (eds), The Neuropsychology of Schizophrenia, pp. 197-213. Erlbaum, Hove, UK.

Fleming, K., Goldberg, T.E., Binks, S., Randolph, C., Gold, J.M. and Weinberger, D.R., 1997. Visuospatial working memory in patients with schizophrenia. Biological Psychiatry, 41, 43-49. 
Franck, N., Farrer, C., Georieff, N., Marie-Cardine, M. et al., 2001. Defective recognition of one's own actions in schizophrenic patients. American Journal of Psychiatry, 158, 454-459.

Friedman, J.I., Harvey, P.D., Kemether, E., Byne, W. and Davis, K.L., 1999a. Cognitive and functional changes with aging in schizophrenia. Biological Psychiatry, 46, 921-928.

Friedman, J.I., Temporini, H. and Davis, K.L., 1999b. Pharmacologic strategies for augmenting cognitive performance in schizophrenia. Biological Psychiatry, 45, 1-16.

Frith, C.D., 1992. The Cognitive Neuropsychology of Schizophrenia. Erlbaum, Hove, UK.

Frith, C.D. and Corcoran, R., 1996. Exploring 'theory of mind' in people with schizophrenia. Psychological Medicine, 26, 521-530.

Frith, C.D. and Done, D.J., 1989. Experiences of alien control in schizophrenia reflect a disorder in the central monitoring of action. Psychological Medicine, 19, 359-363.

Fucetola, R., Seidman, L.J., Kremen, W.S., Faraone, S.V., Goldstein, J.M. and Tsuang, M.T., 2000. Age and neuropsychologic function in schizophrenia: a decline in executive abilities beyond that observed in healthy volunteers. Biological Psychiatry, 48, 137-146.

Funahashi, S., Bruce, C.J. and Goldman-Rakic, P.S., 1989. Mnemonic coding of visual space in the monkey's dorsolateral prefrontal cortex. Journal of Neurophysiology, 61, 1-19.

Fuster, J.M., 1989. The Prefrontal Cortex (2nd edn). Raven Press, New York.

Gilvarry, C., Takei, N., Russell, A., Rushe, T., Hemsley, D. and Murray, R.M., 2000. Premorbid IQ in patients with functional psychosis and their first-degree relatives. Schizophrenia Research, 41, 417-429.

Gilvarry, C.M., Russel, A., Jones, P., Sham, P., Hemsley, D. and Murray, R.M., 2001. Verbal fluency in patients with schizophrenia and affective psychosis and their first-degree relatives. Psychological Medicine, 31, 695-704.

Gold, J.M., Carpenter, C., Randolph, C., Goldberg, T.E. and Weinberger, D.R., 1997. Auditory working memory and Wisconsin Card Sorting Test performance in schizophrenia. Archives of General Psychiatry, 54 $159-165$.

Gold, S., Arndt, S., Nopoulos, P., O'Leary, D.S. and Andreasen, N.C., 1999. Longitudinal study of cognitive function in first-episode and recentonset schizophrenia. American Journal of Psychiatry, 156, 1342-1348.

Goldberg, T.E. and Weinberger, D.R., 1994. Schizophrenia, training paradigms, and the Wisconsin Card Sorting Test redux. Schizophrenia Research, 11, 291-296.

Goldberg, T.E., Ragland, J.D., Torrey, E.F., Gold, J.M., Bigelow, L.B. and Weinberger, D.R., 1990. Neuropsychological assessment of monozygotic twins discordant for schizophrenia. Archives of General Psychiatry, 47, 1066-1072.

Goldberg, T.E., Greenberg, R.D., Griffin, S.J. et al., 1993a. The effect of clozapine on cognition and psychiatric symptoms in patients with schizophrenia. British Journal of Psychiatry, 162, 43-48.

Goldberg, T.E., Hyde, T.M., Kleinman, J.E. and Weinberger, D.R., 1993b. Course of schizophrenia: neuropsychological evidence for a static encephalopathy. Schizophrenia Bulletin, 19, 797-804.

Goldberg, T.E., Torrey, E.F., Berman, K.F. and Weinberger, D.R., 1994 Relations between neuropsychological performance and brain morphological and physiological measures in monozygotic twins discordant for schizophrenia. Psychiatry Research, 55, 51-61.

Goldman, P.S. and Rosvold, H.E., 1970. Localization of function within the dorsolateral prefrontal cortex of the rhesus monkey. Experimental Neurology, 27, 291-304.

Goldman-Rakic, P.S., 1994. Working memory dysfunction in schizophrenia. Journal of Neuropsychiatry and Clinical Neuroscience, 6, 348-357.

Goldstein, G., Beers, S.R. and Shemansky, W.J., 1996. Neuropsychological differences between schizophrenic patients with heterogeneous Wisconsin Card Sorting Test performance. Schizophrenia Research, 21, 13-18.

Granholm, E., Morris, S., Asarnow, R.F., Chock, D. and Jeste, D.V., 2000. Accelerated age-related decline in processing resources in schizophrenia: evidence from pupillary responses recorded during the span of apprehension task. Journal of the International Neuropsychological Society, $\mathbf{6}$, $30-43$.

Gray, N.S., Hemsley, D.R. and Gray, J.A., 1992. Abolition of latent inhibition in acute but not chronic schizophrenics. Neurology, Psychiatry, and Brain Research, 1, 83-89.

Green, M.F., 1996. What are the functional consequences of neurocognitive deficits in schizophrenia? American Journal of Psychiatry, 153, 321-330.
Green, M.F., 1998. Schizophrenia from a Neurocognitive Perspective: Probing the Impenetrable Darkness. Allyn \& Bacon, Boston, MA.

Green, M.F. and Nuechterlein, K.H., 1999. Should schizophrenia be treated as a neurocognitive disorder? Schizophrenia Bulletin, 25, 309-318.

Green, M. and Walker, E., 1986. Attentional performance in positiveand negative-symptom schizophrenia. Journal of Nervous and Mental Disease, 174, 208-213.

Green, M.F., Satz, P., Ganzell, S. and Vaclav, J.F., 1992. Wisconsin Card Sorting Test performance in schizophrenia: remediation of a stubborn deficit. American Journal of Psychiatry, 149, 62-67.

Hans, S.L., Marcus, J., Nuechterlein, K.H., Asarnow, R.F., Styr, B. and Auerbach, J.G., 1999. Neurobehavioral deficits at adolescence in children at risk for schizophrenia. Archives of General Psychiatry, 56, $741-748$.

Harvey, P.D., White, L., Parrella, M. et al., 1995. The longitudinal stability of cognitive impairment in schizophrenia: mini-mental state scores at one- and two-year follow-ups in geriatric in-patients. British Journal of Psychiatry, 166, 630-633.

Harvey, P.D., Parrella, M., White, L., Mohs, R.C., Davidson, M. and Davis, K.L., 1999a. Convergence of cognitive and adaptive decline in late-life schizophrenia. Schizophrenia Research, 35, 77-84.

Harvey, P.D., Silverman, J.M., Mohs, R.C. et al., 1999b. Cognitive decline in late-life schizophrenia: a longitudinal study of geriatric chronically hospitalized patients. Biological Psychiatry, 45, 32-40.

Haut, M.W., Cahill, J., Cutlip, W.D., Stevenson, J.M., Makela, E.H. and Bloomfield, S.M., 1996. On the nature of Wisconsin Card Sorting Test performance in schizophrenia. Psychiatry Research, 65, 15-22.

Hayes, R.L. and McGrath, J.J., 2000. Cognitive rehabilitation for people with schizophrenia and related conditions (Cochrane review). In: The Cochrane Library, Issue 2, Update Software, Oxford.

Heaton, R.K., 1981. A Manual for the Wisconsin Card Sorting Test. Psychological Assessment Resources, Odessa.

Heaton, R.K. and Crowley, T.J., 1981. Effects of psychiatric disorders and somatic treatments on neuropsychological test results. In: Filskov, S.B. and Boll, T.J.H. (eds), Handbook of Clinical Neuropsychology, pp. 481-525. Wiley, New York.

Heaton, R., Paulsen, J.S., McAdams, L.A. et al., 1994. Neuropsychological deficits in schizophrenics: relationship to age, chronicity, and dementia. Archives of General Psychiatry, 51, 469-476.

Heinrichs, R.W., 1990. Variables associated with Wisconsin Card Sorting Test performance in neuropsychiatric patients referred for assessment. Neuropsychiatry, Neuropsychology, and Behavioral Neurology, 3, $107-112$.

Heinrichs, R.W. and Awad, A.G., 1993. Neurocognitive subtypes of chronic schizophrenia. Schizophrenia Research, 9, 49-58.

Heinrichs, R.W. and Zakzanis, K.K., 1998. Neurocognitive deficit in schizophrenia: a quantitative review of the evidence. Neuropsychology, 12, 426-445.

Heinrichs, R.W., Ruttan, L., Zakzanis, K.K. and Case, D., 1997. Parsing schizophrenia with neurocognitive tests: evidence of stability and validity. Brain and Cognition, 35, 207-224.

Hellman, S.G., Kern, R.S., Neilson, L.M. and Green, M.F., 1998. Monetary reinforcement and Wisconsin Card Sorting performance in schizophrenia: why show me the money? Schizophrenia Research, 34, 67-75.

Hemsley, D.R., 1987. An experimental model for schizophrenia. In: Hafner, H., Gattaz, W.F. and Janzarik, W. (eds), Search for the Cause of Schizophrenia, pp. 179-188. Springer, Heidelberg.

Hemsley, D.R., 1993. A simple (or simplistic?) cognitive model for schizophrenia. Behaviour Research and Therapy, 31, 633-645.

Hemsley, D.R., 1994. A cognitive model for schizophrenia and its possible neural basis. Acta Psychiatrica Scandinavica Suppl, 384, 80-86.

Hindmarch, I. and Tiplady, B., 1994. A comparison of the psychometric effects of remoxipride with those of haloperidol, thioridazine and lorazepam in healthy volunteers. Human Psychopharmacology, 9, 43-49.

Hoff, A.L., Sakuma, M., Wieneke, M., Horon, R., Kushner, M. and DeLisi, L.E., 1999. Longitudinal neuropsychological follow-up study of patients with first-episode schizophrenia. American Journal of Psychiatry, 156, 1336-1341.

Jablensky, A., 1995. Schizophrenia: the epidemiological horizon. In: Hirsch, S.R. and Weinberger, D.R. (eds), Schizophrenia, pp. 206-252. Blackwell Science, Oxford.

Johns, L.C., Rossell, S., Frith, C. et al., 2001. Verbal self-monitoring and auditory verbal hallucinations in patients with schizophrenia. Psychological Medicine, 31, 705-715. 
Johnson, M.K., Raye, C.L., Foley, H.J. and Foley, M.A., 1981. Cognitive operations and decision bias in reality monitoring. American Journal of Psychology, 94, 37-64.

Johnson, M.K., Hashtroudi, S. and Lindsay, D.S., 1993. Source monitoring. Psychological Bulletin, 114, 3-28.

Johnstone, E.C. and Frith, C.D., 1996. Validation of three dimensions of schizophrenic symptoms in a large unselected sample of patients. Psychological Medicine, 26, 669-679.

Jones, P., Guth, C., Lewis, S. and Murray, R., 1994a. Low intelligence and poor educational achievement precede early onset schizophrenic psychosis. In: David, A.S. and Cutting, J.C. (eds), The Neuropsychology of Schizophrenia, pp. 131-144. Erlbaum, Hove, UK.

Jones, P., Rogers, B., Murray, R. and Marmot, M., 1994b. Child development risk factors for adult schizophrenia in the British 1946 birth cohort. Lancet, 344, 1398-1402.

Keefe, R.S., 1995. The contribution of neuropsychology to psychiatry. American Journal of Psychiatry, 152, 6-15.

Keefe, R.S., Arnold, M.C., Bayen, U.J. and Harvey, P.D., 1999a. Source monitoring deficits in patients with schizophrenia: a multinomial modelling analysis. Psychological Medicine, 29, 903-914.

Keefe, R.S.E., Silva, S.G., Perkins, D.O. and Lieberman, J.A., 1999b. The effects of atypical antipsychotic drugs on neurocognitive impairment in schizophrenia: a review and meta-analysis. Schizophrenia Bulletin, 25, 201-222.

Kendler, K.S., McGuire, M., Gruenberg, A.M., O'Hare, A., Spellman, M. and Walsh, D., 1993. The Roscommon Family Study. III. Schizophreniarelated personality disorders in relatives. Archives of General Psychiatry, 50, 781-788.

Kendler, K.S., Gruenberg, A.M. and Kinney, D.K., 1994. Independent diagnoses of adoptees and relatives as defined by DSM-III in the provincial and national samples of the Danish Adoption Study of Schizophrenia. Archives of General Psychiatry, 51, 456-468.

Kern, R.S., Green, M.F. and Wallace, C.J., 1997. Declarative and procedural learning in schizophrenia: a test of the integrity of divergent memory systems. Cognitive Neuropsychiatry, 2, 39-50.

King, D.J., 1990. The effect of neuroleptics on cognitive and psychomotor function. British Journal of Psychiatry, 157, 799-811.

King, D.J., 1994. Psychomotor impairment and cognitive disturbances induced by neuroleptics. Acta Psychiatrica Scandinavica, 89, 53-58.

Krabbendam, L., de Vugt, M.E., Derix, M.M. and Jolles, J., 1999. The behavioural assessment of the dysexecutive syndrome as a tool to assess executive functions in schizophrenia. Clinical Neuropsychologist, 13, $370-375$.

Krabbendam, L., Derix, M.M., Honig, A. et al., 2000. Cognitive performance in relation to MRI temporal lobe volume in schizophrenic patients and healthy control subjects. Journal of Neuropsychiatry and Clinical Neurosciences, 12, 251-256.

Krabbendam, L., Marcelis, M., Delespaul, P., Jolles, J. and Van Os, J. 2001. Single or multiple cognitive risk factors in schizophrenia? American Journal of Medical Genetics (Neuropsychiatric Genetics), 105, $183-188$.

Kraepelin, E., 1919/1971. Dementia Praecox and Paraphrenia (transl. by Barclay, R.M.) (Robertson, G., ed.). pp. 282-329. R.E. Krieger, Huntington, UK.

Kremen, W.S., Buka, S.L., Seidman, L.J., Goldstein, J.M., Koren, D. and Tsuang, M.T., 1998. IQ decline during childhood and adult psychotic symptoms in a community sample: a 19-year longitudinal study. American Journal of Psychiatry, 155, 672-677.

Kremen, W.S., Seidman, L.J., Pepple, J.R., Lyons, M.J., Tsuang, M.T. and Faraone, S.V., 1994. Neuropsychological risk indicators for schizophrenia: a review of family studies. Schizophrenia Bulletin, 20, 103-119.

Kwapil, T.R., Hegley, D.C., Chapman, L.J. and Chapman, J.P., 1990. Facilitation of word recognition by semantic priming in schizophrenia. Journal of Abnormal Psychology, 99, 215-221.

Landrø, N.I., 1994. Memory function in schizophrenia. Acta Psychiatrica Scandinavica, 90(Suppl 384), 87-94.

Lenzenweger, M.F. and Gold, J.M., 2000. Auditory working memory and verbal recall memory in schizotypy. Schizophrenia Research, $\mathbf{4 2}$, $101-110$.

Lenzenweger, M.F. and Korfine, L., 1994. Perceptual aberrations, schizotypy, and the Wisconsin Card Sorting Test. Schizophrenia Bulletin, 20, 345-357.

Leslie, A.M., 1987. Pretense and representation: the origins of 'theory of mind'. Psychological Review, 94, 412-426.
Lezak, M.D., 1982. The problem of assessing executive functions. International Journal of Psychology, 17, 281-297.

Lezak, M.D., 1995. Neuropsychological assessment (3rd edn). Oxford University Press, Oxford.

Liddle, P.F., 1987. The symptoms of chronic schizophrenia: a re-examination of the positive-negative dichotomy. British Journal of Psychiatry, 151, $145-151$.

Liddle, P.F. and Morris, D.L., 1991. Schizophrenic syndromes and frontal lobe performance. British Journal of Psychiatry, 158, 340-345.

Lieberman, J.A., 1999. Is schizophrenia a neurodegenerative disorder? A clinical and neurobiological perspective. Biological Psychiatry, 46, 729-739.

Lubow, R.E. and Gewirtz, J.C., 1995. Latent inhibition in humans: data theory, and implications for schizophrenia. Psychological Bulletin, 117, 87-103.

Maher, B.A., Manschreck, T.C., Redmond, D. and Beaudette, S., 1996 Length of illness and the gradient from positive to negative semantic priming in schizophrenic patients. Schizophrenia Research, 22 $127-132$.

Martinez Aran, A., Vieta, E., Colom, F. et al., 2000. Cognitive dysfunctions in bipolar disorder: evidence of neuropsychological disturbances. Psychotherapy and Psychosomatics, 69, 2-18.

McKenna, P.J., Tamlyn, D., Lund, C.E., Mortimer, A.M., Hammond, S. and Baddeley, A.D., 1990. Amnesic syndrome in schizophrenia. Psychological Medicine, 20, 967-972.

Medalia, A., Gold, J.M. and Merriam, A., 1988. The effects of neuroleptics on neuropsychological test results of schizophrenics. Archives of Clinical Neuropsychology, 3, 249-271.

Medalia, A., Revheim, N. and Casey, M., 2000. Remediation of memory disorders in schizophrenia. Psychological Medicine, 30, 1451-1459.

Medalia, A., Revheim, N. and Casey, M., 2001. The remediation of problem-solving skills in schizophrenia. Schizophrenia Bulletin, 27, 259-267.

Mirsky, A.F., Ingraham, L.J. and Kugelmass, S., 1995a. Neuropsychological assessment of attention and its pathology in the Israeli cohort. Schizophrenia Bulletin, 21, 193-204.

Mirsky, A.F., Kugelmass, S., Ingraham, L.J., Frenkel, E. and Nathan, M., 1995b. Overview and summary: twenty-five-year followup of high-risk children. Schizophrenia Bulletin, 21, 227-239.

Mlakar, J., Jensterle, J. and Frith, C.D., 1994. Central monitoring deficiency and schizophrenic symptoms. Psychological Medicine, 24, 557-564.

Mohamed, S., Paulsen, J.S., O'Leary, D., Arndt, S. and Andreasen, N., 1999. Generalized cognitive deficits in schizophrenia: a study of firstepisode patients. Archives of General Psychiatry, 56, 749-754.

Morice, R., 1990. Cognitive inflexibility and pre-frontal dysfunction in schizophrenia and mania. British Journal of Psychiatry, 157, 50-54.

Moritz, S. and Mass, R., 1997. Reduced cognitive inhibition in schizotypy. British Journal of Clinical Psychology, 36, 365-376.

Morrison, A.P. and Haddock, G., 1997. Cognitive factors in source monitoring and auditory hallucinations. Psychological Medicine, 27, $669-679$.

Mortimer, A.M., 1997. Cognitive function in schizophrenia: do neuroleptics make a difference? Pharmacology Biochemistry and Behavior, 56, 789-795.

Nelson, E.B., Sax, K.W. and Strakowski, S.M., 1998. Attentional performance in patients with psychotic and nonpsychotic major depression and schizophrenia. American Journal of Psychiatry, 155, 137-139.

Nopoulos, P., Flashman, L., Flaum, M., Arndt, S. and Andreasen, N., 1994. Stability of cognitive functioning early in the course of schizophrenia. Schizophrenia Research, 14, 29-37.

Nuechterlein, K.H. and Dawson, M.E., 1984. A heuristic vulnerability/stress model of schizophrenic episodes. Schizophrenia Bulletin, 10 , 300-312.

Nuechterlein, K.H., Dawson, M.E. and Green, M.F., 1994. Informationprocessing abnormalities as neuropsychological vulnerability indicators to schizophrenia. Acta Psychiatrica Scandinavica, 90(Suppl 384), $71-79$.

O'Leary, D.S., Flaum, M., Kesler, M.L., Flashman, L.A., Arndt, S. and Andreasen, N.C., 2000. Cognitive correlates of the negative, disorganized, and psychotic symptom dimensions of schizophrenia. Journal of Neuropsychiatry and Clinical Neuroscience, 12, 4-15.

Palmer, B.W., Heaton, R.K., Paulsen, J.S. et al., 1997. Is it possible to be schizophrenic yet neuropsychologically normal? Neuropsychology, 11, 437-446. 
Pantelis, C., Barnes, T.R.E., Nelson, H.E. et al., 1997. Frontal striatal cognitive deficits in patients with chronic schizophrenia. Brain, 120, $1823-1843$

Park, S. and Holzman, P.S., 1992. Schizophrenics show spatial working memory deficits. Archives of General Psychiatry, 49, 975-982.

Park, S., Holzman, P.S. and Lenzenweger, M.F., 1995. Individual differences in spatial working memory in relation to schizotypy. Journal of Abnormal Psychology, 104, 355-363.

Paulsen, J.S., Heaton, R.K., Sadek, J.R. et al., 1995. The nature of learning and memory impairments in schizophrenia. Journal of the International Neuropsychological Society, 1, 88-99.

Payne, R.W., 1973. Cognitive abnormalities. In: Eysenck, H.J. (ed.), Handbook of Abnormal Psychology, pp. 420-483. Pitman, London.

Perry, W., Heaton, R.K., Potterat, E., Roebuck, T., Minassian, A. and Braff, D.L., 2001. Working memory in schizophrenia: transient 'online' storage versus executive functioning. Schizophrenia Bulletin, 27, $157-176$

Peters, E.R., Pickering, A.D. and Hemsley, D.R., 1994. 'Cognitive inhibition' and positive symptomatology in schizotypy. British Journal of Clinical Psychology, 33, 33-48.

Premack, D. and Woodruff, G., 1978. Does the chimpanzee have a 'theory of mind'? Behavioural and Brain Sciences, 4, 515-526.

Riley, E.M., McGovern, D., Mockler, D. et al., 2000. Neuropsychological functioning in first-episode psychosis: evidence of specific deficits. Schizophrenia Research, 43, 47-55.

Rossi, A., Daneluzzo, E., Mattei, P., Bustini, M., Casacchia, M. and Stratta, P., 1997a. Wisconsin card sorting test and Stroop test performance in schizophrenia: a shared construct. Neuroscience Letters, 226, 87-90.

Rossi, A., Mancini, F., Stratta, P. et al., 1997b. Risperidone, negative symptoms and cognitive deficit in schizophrenia: an open study. Acta Psychiatrica Scandinavica, 95, 40-43.

Rund, B.R., 1998. A review of longitudinal studies of cognitive functions in schizophrenia patients. Schizophrenia Bulletin, 24, 425-435.

Sarfati, Y. and Hardy Bayle, M.C., 1999. How do people with schizophrenia explain the behaviour of others? A study of theory of mind and its relationship to thought and speech disorganization in schizophrenia. Psychological Medicine, 29, 613-620.

Sarfati, Y., Hardy Bayle, M.C., Besche, C. and Widlocher, D., 1997. Attribution of intentions to others in people with schizophrenia: a non-verba exploration with comic strips. Schizophrenia Research, 25, 199-209.

Sarfati, Y., Hardy Bayle, M.C., Brunet, E. and Widlocher, D., 1999. Investigating theory of mind in schizophrenia: influence of verbalization in disorganized and non-disorganized patients. Schizophrenia Research, 37, $183-190$.

Saykin, A.J., Gur, R.C., Gur, R.E. et al., 1991. Neuropsychological function in schizophrenia: selective impairment in memory and learning. Archives of General Psychiatry, 48, 618-624.

Saykin, A.J., Shtasel, D.L., Gur, R.E. et al., 1994. Neuropsychological deficits in neuroleptic naive patients with first-episode schizophrenia. Archives of General Psychiatry, 51, 124-131.

Seaton, B.E., Allen, D.N., Goldstein, G., Kelley, M.E. and van Kammen, D.P., 1999. Relations between cognitive and symptom profile heterogeneity in schizophrenia. Journal of Nervous and Mental Disease, $\mathbf{1 8 7}$ 414-419.

Seidman, L.J., Pepple, J.R., Faraone, S.V. et al., 1993. Neuropsychological performance in chronic schizophrenia in response to neuroleptic dose reduction. Biological Psychiatry, 33, 575-584.

Seltzer, J., Conrad, C. and Cassens, G., 1997. Neuropsychological profiles in schizophrenia: paranoid versus undifferentiated distinctions. Schizophrenia Research, 23, 131-138.

Servan-Schreiber, D., Cohen, J.D. and Steingard, S., 1996. Schizophrenic deficits in the processing of context: a test of a theoretical model. Archives of General Psychiatry, 53, 1105-1112.

Shallice, T., 1982. Specific impairments of planning. Philosophical Transactions of the Royal Society of London. Series B: Biological Sciences, 298, 199-209.

Shallice, T. and Burgess, P.W., 1991. Deficits in strategy application following frontal lobe damage in man. Brain, 114, 727-741.

Shallice, T., Burgess, P.W. and Frith, C.D., 1991. Can the neuropsychological case-study approach be applied to schizophrenia? Psychological Medicine, 21, 661-673.

Spitzer, M., 1993. The psychopathology, neuropsychology, and neurobiology of associative and working memory in schizophrenia. European Archives of Psychiatry and Clinical Neuroscience, 243, 57-70.
Spitzer, M., Braun, U., Maier, S., Hermle, L. and Maher, B.A., 1993. Indirect semantic priming in schizophrenic patients. Schizophrenia Research, 11, $71-80$.

Spohn, H.E. and Strauss, M.E., 1989. Relation of neuroleptic and anticholinergic medication to cognitive functions in schizophrenia. Journal of Abnormal Psychology, 98, 367-380.

Stirling, J.D., Hellewell, J.S.E. and Quraishi, N., 1998. Self-monitoring dysfunction and the schizophrenic symptoms of alien control. Psychological Medicine, 28, 675-683.

Stratta, P., Rossi, A., Mancini, F., Cupillari, M., Mattei, P. and Casacchia, M., 1993. Wisconsin Card Sorting Test performance and educational level in schizophrenic and control samples. Neuropsychiatry, Neuropsychology, and Behavioral Neurology, 6, 149-153.

Strauss, M.E., 1993. Relations of symptoms to cognitive deficits in schizophrenia. Schizophrenia Bulletin, 19, 215-231.

Stroop, J.R., 1935. Studies of interference in serial verbal reactions. Journal of Experimental Psychology, 18, 643-662.

Sullivan, E.V., Mathalon, D.H., Zipursky, Z.B., Kersteen-Tucker, Z., Knight, R.T. and Pfefferbaum, A., 1993. Factors of the Wisconsin Card Sorting Test as measures of frontal-lobe function in schizophrenia and in chronic alcoholism. Psychiatry Research, 46, 175-199.

Suslow, T., Junghanns, K., Weitzsch, C. and Arolt, V., 1998. Relations between neuropsychological vulnerability markers and negative symptoms in schizophrenia. Psychopathology, 31, 178-187.

Suslow, T., Schonauer, K. and Arolt, V., 2001. Attention training in the cognitive rehabilitation of schizophrenic patients: a review of efficacy studies. Acta Psychiatrica Scandinavica, 103, 15-23.

Tipper, S.P., 1985. The negative priming effect: inhibitory priming by ignored objects. Quarterly Journal of Experimental Psychology, 37A, 571-590.

Trestman, R.L., Keefe, R.S., Mitropoulou, V. et al., 1995. Cognitive function and biological correlates of cognitive performance in schizotypal personality disorder. Psychiatry Research, 59, 127-136.

Tsuang, M.T., 1993. Genotypes, phenotypes, and the brain: a search for connections in schizophrenia. British Journal of Psychiatry, 163, 299-307.

Tulving, E., 1983. Elements of Episodic Memory. Oxford University Press, Oxford.

Van den Bosch, R.J., Rombouts, R.P. and van Asma, M.J., 1996. What determines continuous performance task performance? Schizophrenia Bulletin, 22, 643-651.

Van der Does, A.J., Dingemans, P.M., Linszen, D.H., Nugter, M.A. and Scholte, W.F., 1996. Symptoms, cognitive and social functioning in recent-onset schizophrenia: a longitudinal study. Schizophrenia Research, 19, $61-71$.

Velligan, D.I., Mahurin, R.K., Diamond, P.L., Hazleton, B.C., Eckert, S.L. and Miller, A.L., 1997. The functional significance of symptomatology and cognitive function in schizophrenia. Schizophrenia Research, 25, $21-31$.

Velligan, D.I., Bow Thomas, C.C., Mahurin, R.K., Miller, A.L. and Halgunseth, L.C., 2000. Do specific neurocognitive deficits predict specific domains of community function in schizophrenia? Journal of Nervous and Mental Disease, 188, 518-524.

Verdoux, H., Magnin, E. and Bourgeois, M., 1995. Neuroleptic effects on neuropsychological test performance in schizophrenia. Schizophrenia Research, 14, 133-139.

Voglmaier, M.M., Seidman, L.J., Salisbury, D. and McCarley, R.W., 1997. Neuropsychological dysfunction in schizotypal personality disorder: a profile analysis. Biological Psychiatry, 41, 530-540.

Voglmaier, M.M., Seidman, L.J., Niznikiewicz, M.A., Dickey, C.C., Shenton, M.E. and McCarley, R.W., 2000. Verbal and nonverbal neuropsychological test performance in subjects with schizotypal personality disorder. American Journal of Psychiatry, 157, 787-793.

Voruganti, L.N., Heslegrave, R.J. and Awad, A.G., 1997. Neurocognitive correlates of positive and negative syndromes in schizophrenia. Canadian Journal of Psychiatry, 42, 1066-1071.

Weickert, T.W., Goldberg, T.E., Gold, J.M., Bigelow, L.B., Egan, M.F. and Weinberger, D.R., 2000. Cognitive impairments in patients with schizophrenia displaying preserved and compromised intellect. Archives of General Psychiatry, 57, 907-913.

Weinberger, D.R., 1987. Implications of normal brain development for the pathogenesis of schizophrenia. Archives of General Psychiatry, 44, $660-669$. 
Williams, L.M., 1995. Further evidence for a multidimensional personality disposition to schizophrenia in terms of cognitive inhibition. British Journal of Clinical Psychology, 34, 193-213.

Wilson, B.A., Alderman, N., Burgess, P.W., Emslie, H.E. and Evans, J.J., 1996. Behavioural Assessment of the Dysexecutive Syndrome. Thames Valley Test Company, Bury St Edmunds, UK.

Wykes, T., Reeder, C., Corner, J., Williams, C. and Everitt, B., 1999. The effects of neurocognitive remediation on executive processing in patients with schizophrenia. Schizophrenia Bulletin, 25, 291-307.
Zakzanis, K.K., Leach, L. and Kaplan, E., 1999. Neuropsychological Differential Diagnosis. Swets \& Zeitlinger, Lisse, Netherlands.

Zalewski, C., Johnson Selfridge, M.T., Ohriner, S., Zarrella, K. and Seltzer,

J.C., 1998. A review of neuropsychological differences between paranoid and nonparanoid schizophrenia patients. Schizophrenia Bulletin, 24, $127-145$.

Zubin, J. and Spring, B., 1977. Vulnerability: a new view of schizophrenia. Journal of Abnormal Psychology, 86, 103-126. 
